\title{
Seasonal and regional variations of long- term changes in upper-tropospheric jets from reanalyses
}

Article

Accepted Version

Manney, G. L. and Hegglin, M. I. (2018) Seasonal and regional variations of long-term changes in upper-tropospheric jets from reanalyses. Journal of Climate, 31 (1). pp. 423-448. ISSN 1520-0442 doi: https://doi.org/10.1175/JCLI-D-17-0303.1 Available at https://centaur.reading.ac.uk/73555/

It is advisable to refer to the publisher's version if you intend to cite from the work. See Guidance on citing.

To link to this article DOI: http://dx.doi.org/10.1175/JCLI-D-17-0303.1

Publisher: American Meteorological Society

All outputs in CentAUR are protected by Intellectual Property Rights law, including copyright law. Copyright and IPR is retained by the creators or other copyright holders. Terms and conditions for use of this material are defined in the End User Agreement.

$\underline{\text { www.reading.ac.uk/centaur }}$

\section{CentAUR}


Central Archive at the University of Reading

Reading's research outputs online 


\section{Seasonal and Regional Variations of Long-Term Changes in}

\section{Upper Tropospheric Jets from Reanalyses}

Michaela I Hegglin

7 * Corresponding author address: Dept. of Physics, New Mexico Institute of Mining and Technol-

8 ogy, Socorro, New Mexico, 87801, USA.

9 E-mail: manney@nwra.com

${ }_{10}^{\dagger}$ Also at New Mexico Institute of Mining and Technology, Socorro, New Mexico, USA. 
ABSTRACT 
12 are assessed using five modern reanalyses, MERRA and MERRA-2, ERA-

13 Interim, JRA-55, and NCEP-CFSR. Changes are computed from jet locations

${ }_{14}$ evaluated daily at each longitude to analyze regional and seasonal variations.

15 The changes in subtropical and polar (eddy-driven) jets are evaluated sepa-

${ }_{16}$ rately. Good agreement among the reanalyses in many regions and seasons

17 provides confidence in the robustness of the diagnosed trends. Jet shifts show

${ }_{18}$ strong regional and seasonal variations, resulting in changes that are not ro-

${ }_{19}$ bust in zonal or annual means. Robust changes in the subtropical jet indicate

20 tropical widening over Africa except during northern hemisphere (NH) spring,

${ }_{21}$ and tropical narrowing over the eastern Pacific in $\mathrm{NH}$ winter. The Southern

${ }_{22}$ Hemisphere (SH) polar jet shows a robust poleward shift, while the NH po-

${ }_{23}$ lar jet shifts equatorward in most regions/seasons. Both subtropical and polar

${ }_{24}$ jet altitudes typically increase; these changes are more robust in the $\mathrm{NH}$ than

${ }_{25}$ in the SH. Subtropical jet windspeeds have generally increased in winter and

${ }_{26}$ decreased in summer, while polar jet windspeeds weakened (strengthened)

${ }_{27}$ over Africa and eastern Asia (elsewhere) during winter in both hemispheres.

${ }_{28}$ The Asian monsoon has increased in area and appears to have shifted slightly

29 westward towards Africa. Our results highlight the importance of understand-

so ing regional and seasonal variations when quantifying long term changes in

${ }_{31}$ jet locations, the mechanisms for those changes, and their potential human

${ }_{32}$ impacts. Comparison of multiple reanalyses is a valuable tool for assessing

з3 the robustness of jet changes. 


\section{Introduction}

The upper tropospheric (UT) jet streams are a key component of the atmospheric circulation and closely linked with weather and climate phenomena such as storm tracks, precipitation, and extreme events (Koch et al. 2006; Harnik et al. 2016; Mann et al. 2017, and references therein). The UT jets and the tropopause are themselves sensitive to climate change and ozone depletion (e.g., Seidel and Randel 2006; Lorenz and DeWeaver 2007; McLandress et al. 2011; WMO 2011; Hudson 2012; Grise et al. 2013; Waugh et al. 2015), as well as to natural modes of variability such as ENSO and QBO (Hudson 2012; Lin et al. 2014, 2015; Olsen et al. 2016, and references therein).

Upper tropospheric jets are often categorized conceptually as radiatively-driven or eddy-driven jets. Radiatively-driven jets arise via heating of the tropics, which drives the Hadley circulation and through conservation of angular momentum leads to strong westerly winds in the subtropical upper troposphere (e.g., Held and Hou 1980). Eddy-driven jets are maintained by disturbances in the atmospheric zonal mean flow (Held and Hoskins 1985; Lorenz and Hartmann 2003; Robinson 2006; Baldwin et al. 2007; Garfinkel et al. 2013, and references therein). However, observations show a complex seasonally and regionally varying picture in which distinct radiatively-driven or eddy-driven jets cannot be identified (e.g., Manney et al. 2014), consistent with idealized modeling studies that show a complex interplay of these processes (e.g., Lee and Kim 2003). The observed complex jet structures arise primarily from the distributions of land-mass and orography (e.g., Hoskins and Valdes 1990; Held et al. 2002). Because of the combination of several mechanisms involved in generating and maintaining the upper tropospheric jets (Lee and Kim 2003; Wang and Lee 2016, and references therein), it is not straightforward to predict how they would respond to climate change. 
Changes in climatological jet stream characteristics (latitude, altitude, windspeed) are, however, expected to lead to changes in weather patterns and regional climate impacts (see, e.g., reviews by Lucas et al. (2014) and Harnik et al. (2016)). UT jet variations have been linked to rainfall changes and hence water stress for populations in the subtropics (e.g., Price et al. 1998; Raible et al. 2004; Karnauskas and Ummenhofer 2014; Lucas et al. 2014; Screen and Simmonds 2014; Huang et al. 2015; Xie et al. 2015). Regional rainfall decline in Australia has been associated with a poleward shift of the jets (and accompanying rain-producing storms) that is in turn linked to circulation changes caused by Antarctic ozone depletion (Kang et al. 2011; Thompson et al. 2011; Delworth and Zeng 2014; Bai et al. 2016). Jet variability has also been linked to destructive wind storms (e.g., Pinto et al. 2009, 2014; Gómara et al. 2014; Messori and Caballero 2015; Messori et al. 2016) and extreme temperature events (e.g., Cohen et al. 2014; Screen and Simmonds 2014; Harnik et al. 2016; Röthlisberger et al. 2016).

Both modeling and observational studies suggest a poleward shift of the subtropical jet (thus widening of the tropical belt) resulting from the changing climate (e.g., Santer et al. 2003; Lorenz and DeWeaver 2007; Seidel et al. 2008; Strong and Davis 2007, 2008; Archer and Caldeira 2008; Davis and Rosenlof 2012; Lucas et al. 2014; Staten et al. 2016). A possible mechanism for this is increasing subtropical upper tropospheric meridional temperature gradients, which would strengthen the jet (Held 1993; Lucas and Nguyen 2015; Barnes and Screen 2015, and references therein). Different observational datasets and methods yield widely varying and highly uncertain estimates of tropical expansion, with most estimates under one degree per decade (e.g. Birner et al. 2014; Lucas et al. 2014) and additional uncertainties in the asymmetry between the hemispheres and the seasonality of the expansion rates (e.g., Lucas et al. 2014). Several studies suggest strong regional variations in tropical width, including regions of narrowing rather than widening (e.g. Lucas et al. 2012; Peña-Ortiz et al. 2013; Lucas and Nguyen 2015). Robust information on regional 
variations and long-term changes is crucial for planning and climate change adaptation. The annual and/or zonal averaging commonly used may mask clear signals in jet trends in individual regions and seasons, from which more information on the main drivers and processes behind the changes could be gained (Lucas et al. 2014; Zappa et al. 2015). In the Southern Hemisphere (SH), modeling studies indicate that the poleward shift in the edge of the tropics has been exacerbated by chemical ozone depletion, especially during Austral summer, and will be counteracted to some extent by the recovery of the ozone hole (e.g., Son et al. 2010; Arblaster et al. 2011; McLandress et al. 2011). Waugh et al. (2015) showed that the extent to which the models are capable of reproducing observed trends in jet position depends strongly on their accuracy in representing ozone depletion and tropical sea-surface temperatures. Current models generally do not capture the full magnitude of observed changes, although this may be more closely related to natural internal variability than to incorrect representation of anthropogenic forcings (Garfinkel et al. 2015).

Many studies do not clearly separate trends in the subtropical jet from those in the eddy-driven or "polar" jet. The many potential feedbacks and interactions involved in the response of the polar jet to a changing climate (Simpson et al. 2014; Barnes and Screen 2015; Woollings et al. 2016, and references therein) make it difficult to argue for an expected sign of changes in its strength or position. Moreover, considerable controversy exists as to the effects of Arctic Amplification (Serreze and Barry 2011, and references therein) on the position and strength of the eddy-driven jet (Cohen et al. 2014; Screen and Simmonds 2014; Barnes and Polvani 2015; Barnes and Screen 2015; Overland et al. 2016; Shepherd 2016, and references therein). Temperature gradients in the lower troposphere may be expected to weaken in response to Arctic amplification, which would lead to a weakening and equatorward shift of the jets (Held 1993; Barnes and Screen 2015, and references therein). However, many models predict a strengthening of upper tropospheric temperature gradients, which would lead to a strengthening and poleward shift of the jets - lower and upper 
tropospheric jet responses may thus not be the same. Moreover, dynamical feedbacks resulting from the changing background winds (e.g., from changing waveguide conditions that affect wave activity, heat, and momentum fluxes) could play as large as or a larger role than changes in temperature gradients (e.g., Simpson et al. 2009; Woollings et al. 2016). The modeled response of the polar jet to climate change shows a tendency for models with well-resolved stratospheres to have a weaker poleward, or even an equatorward, shift of the polar jet compared to low-top models (e.g., Butler et al. 2010; Sigmond and Scinocca 2010; Scaife et al. 2012; Screen et al. 2013; Manzini et al. 2014). As is the case for the subtropical jet, modeling and observational studies suggest regional and seasonal differences in trends in polar jet strength and location (Woollings et al. 2011, 2014; Barnes and Polvani 2013; Peña-Ortiz et al. 2013; Simpson et al. 2014; Simpson and Polvani 2016, and references therein). Results from modeling studies show a large spread and dependence on biases in jet position, with models with more equatorward jets showing stronger poleward shifts (Kidston and Gerber 2010; Woollings et al. 2011; Barnes and Polvani 2013; Simpson and Polvani 2016, and references therein).

Previous studies have examined regional and/or seasonal changes in the jet streams using several methods of characterizing jet locations. Strong and Davis (2007) used National Centers for Environmental Prediction/National Center for Atmospheric Research (NCEP/NCAR) reanalysis data and windspeeds on the "surface of maximum wind" to examine trends in jet streams during northern hemisphere $(\mathrm{NH})$ winter, and found an increase in jet core frequencies and windspeeds over mid-latitudes and a decrease north of $60^{\circ} \mathrm{N}$, suggesting an equatorward shift of the polar jet. Archer and Caldeira (2008) used NCEP/NCAR and European Centre for Medium-range Weather Forcasts (ECMWF) ERA-40 reanalysis data to examine global trends in jet streams in a 2D view using a mass-weighted average throughout the upper troposphere; they showed evidence of a poleward and upward shift of polar jets in both hemispheres and weakening jets with the exception of 
the SH polar jet. Barton and Ellis (2009) examined variability and trends in the north Pacific jet stream using NCEP/NCAR Reanalysis 300-hPa winds, and showed a strengthening jet between 1949 and 2005, with a suggestion of an equatorward shift in its position. Manney et al. (2011) introduced a method of characterizing the upper tropospheric and lower stratospheric jets and the tropopauses in three dimensions. Manney et al. (2014) used this method to describe the climatology of upper tropospheric jets in relation to multiple tropopauses and the stratospheric subvortex using the NASA Global Modeling and Assimilation Office (GMAO) Modern Era Retrospectiveanalysis for Research and Applications (MERRA) reanalysis. Peña-Ortiz et al. (2013) used a jet characterization method that closely parallels that of Manney et al. $(2011,2014)$ to study regional and seasonal trends in the UT jets in the NCEP/NCAR and the NCEP-20th Century (NCEP-20CR) reanalyses; they used a simple latitude criterion to analyze subtropical and polar jets separately in the SH, but could not distinguish these jets in the NH. Overall, they found the largest poleward shift and windspeed increase in the SH polar jet during 1979 through 2008 in austral summer and fall. Their study often showed conflicting results between the two reanalyses; results in many regions and seasons were thus unclear.

The above studies, with the exception of Manney et al. (2011, 2014), used older reanalyses (NCEP/NCAR, ERA-40) that have coarse horizontal (2 to 2.5 degrees) and vertical (standard pressure level grids with $>2 \mathrm{~km}$ levels spacing in the UTLS) resolution, use outdated models and assimilation methods, and have been shown to be inadequate for studies of the UT and stratosphere (see Fujiwara et al. 2017, for a review of reanalysis system characteristics and evaluations). Peña-Ortiz et al. (2013) also used the NCEP-20CR reanalysis, which assimilates only surface observations and also has coarse horizontal and vertical resolution and limited skill in the UT (e.g., Compo et al. 2011; Fujiwara et al. 2017). Manney et al. (2017b) compared jet and tropopause climatologies from five modern high-resolution reanalyses analyzed on their native model levels: 
ECMWF's ERA-Interim, GMAO's MERRA and MERRA-2, NCEP's Climate Forecast System Reanalysis (CFSR) and CFSR version 2 (collectively referred to as "CFSR" hereinafter), and the Japanese Meteorological Agency's JRA-55. Even among these latest generation reanalysis, evaluated at 0.75 to 0.5 degree horizontal resolution, there is substantial sensitivity of results to resolution and assimilation model characteristics.

Thus, both observational and model results have so far shown an inconsistent picture of upper tropospheric jet variability and trends. Observational studies have yet to provide a complete and robust picture with which model results can be evaluated. To achieve this goal, studies must account for seasonal, interannual, and regional variations in jet locations and windspeeds that are expected to be much larger than any underlying climate-induced trends. Moreover, systematic observational studies have not been published that examine long-term changes in the jets using modern reanalyses and jet characterization methods that can distinguish between subtropical and polar jets and elucidate regional and seasonal variations.

In this paper, we extend the methods of Manney et al. $(2011,2014,2017 b)$ to evaluate trends in UTLS jets, using an improved and more robust identification of subtropical and polar jets throughout the year in both hemispheres. We derive changes in both tropical width and polar jet positions for 1979 through 2014. We pay special attention to the three-dimensional character of jet behavior, and quantify trends in location (altitude and latitude) and strength as a function of longitude and season. By analyzing jet cores identified in 3D, and by breaking the analysis down by region and season, we focus on detecting changes that may be diluted or masked in zonal and seasonal averages and in views based solely on windspeed as opposed to jet core characteristics. All evaluations are done for the five modern reanalyses studied by Manney et al. (2017b), using the data on the native model vertical levels and high-resolution horizontal grids with spacing comparable to the model grids; in absence of independent verification methods, consistency or inconsistency among 
the reanalyses is a key measure of the robustness of long-term jet changes. Section 2 describes the reanalysis datasets and the methods used. Sections $3 a$ and $3 b$ present an evaluation of long-term changes in the UTLS subtropical and polar jets, respectively, as represented in the reanalyses. A summary and conclusions are presented in Section 4.

\section{Data and Analysis}

\section{a. Reanalysis Data}

The reanalyses datasets used here are GMAO's MERRA and MERRA-2 (Rienecker et al. 2011; Bosilovich et al. 2015; Molod et al. 2015; Takacs et al. 2016; Gelaro et al. 2017; Global Modeling and Assimilation Office (GMAO) 2015); ECMWF's ERA-Interim (e.g., Dee et al. 2011; Dragani 2011); JMA's JRA-55 (Ebita et al. 2011); and NCEP's CFSR (e.g., Saha et al. 2010). An overview of these reanalyses, the data assimilation systems that produced them, and their primary input datasets, is given by Fujiwara et al. (2017); several different data assimilation methods are used, and, while the major input data sources tend to be quite similar (e.g., operational satellite radiances, radiosondes, etc), there are numerous differences in usage of additional inputs, such as ozone observations (e.g., Dragani 2011; Fujiwara et al. 2017; Wargan et al. 2017; Davis et al. 2017) and recent satellite datasets. There are also differences in the vertical and horizontal grids used in different models. The reanalyses are used on their native model levels; the vertical grids and resolutions are critical to jet and tropopause characterization (e.g., Manney et al. 2017b). The DAS model grids result in $\sim 0.8$ to $1.3 \mathrm{~km}$ vertical resolution in the UTLS; the placement levels and how level spacing changes with height also vary (see Fujiwara et al. 2017, Figure 3, for details). The model horizontal grid spacing for MERRA is $0.5^{\circ}$ latitude $\times 0.667^{\circ}$ longitude; for MERRA-2 it is $0.5^{\circ} \times 0.625^{\circ}$. The other reanalyses use spectral models, and the data used here are on the finest 
latitude/longitude grids publicly available: $0.75^{\circ} \times 0.75^{\circ}$ for ERA-Interim, $0.5^{\circ} \times 0.5^{\circ}$ for CFSR, and a Gaussian grid with approximately $0.5625^{\circ}$ spacing for JRA-55.

The seasonal jet distributions and time variations shown are evaluated for December/January/February running from December 1979 through February 2014, and for other seasons and monthly fields from 1980 through 2014. All the evaluations have been done using all five reanalyses, and, where feasible, all of these are shown. Where it is only feasible to show results from one dataset, MERRA-2, the most recent of these reanalyses, is shown. All results have been checked in each of the reanalyses, and conclusions drawn are based on that full inspection where all could not be shown.

\section{b. Jet and Tropopause Characterization and Analysis}

The JEt and Tropopause Products for Analysis and Characterization (JETPAC) is used to identify and characterize the jets and tropopause. The methods and output products used here are described by Manney et al. (2011, 2014), and briefly summarized below.

An upper tropospheric jet is identified wherever there is a windspeed maximum greater than $40 \mathrm{~m} / \mathrm{s}$; the boundaries of the jet region are the points surrounding that (in both horizontal and vertical directions) where the windspeed drops below $30 \mathrm{~m} / \mathrm{s}$. When more than one maximum above $40 \mathrm{~m} / \mathrm{s}$ appears within a given $30 \mathrm{~m} / \mathrm{s}$ contour, they are defined as separate cores if the latitude distance between them is greater than $10^{\circ}$ or the decrease in windspeed between them is greater than $30 \mathrm{~m} / \mathrm{s}$. These parameters were optimized to approximate as closely as possible the choices that would be made by visual inspection.

Manney et al. $(2011,2014)$ used a simple latitude criterion (appropriate for climatological studies) to identify subtropical and polar UT jets. A more robust physically-based definition is needed for regional and variability studies. Here, the subtropical jet is defined as the most equatorward 
westerly jet for which the thermal tropopause altitude at the equatorward edge of the jet is greater than $13.0 \mathrm{~km}$ and that tropopause altitude drops by at least $2.0 \mathrm{~km}$ from the equatorward to the poleward side of the jet. (The thermal tropopause is identified using the WMO definition (a review of issues related to definition of the thermal tropopause is given by Homeyer et al. 2010).) The polar jet is then defined as the strongest westerly jet poleward of the subtropical jet, or poleward of $40^{\circ}$ latitude if no subtropical jet is identified. The observed upper tropospheric jets often have a hybrid nature (e.g., Lee and Kim 2003) and a spectrum of jet characteristics is seen in the climatology (Manney et al. 2014), and numerous choices could be made for these definitions. The choices made here identify the subtropical jet as one across which a "tropopause break" occurs, consistent with primarily radiative driving, and the polar jet as the dominant jet consistent with primarily eddy driving. These choices allow us to automate identification of the set of jets that best represents these two idealized types. Extensive testing shows that the identification of climatology and variability in jet positions is most sensitive to the use of a physically-based rather than latitude-based criterion to identify the subtropical jet since it often meanders far from its climatological latitude near $30^{\circ}$; once this jet is excluded, the results for the polar jet are generally insensitive to the exact details of how that jet is identified.

Differences between jet core location frequency distributions (as described in detail by Manney et al. 2014) in composites for 10-year periods between the beginning (1980-1989) and end (20052014) of the available record are compared to the 35-year climatology to provide an overview of the spatial distribution of variability and long-term changes in jet core locations. The frequency distributions are normalized by the number of jets that would "fill" each $6^{\circ}$ longitude bin if there was a jet present at each longitude in the bin, and by the number of days in the season, as described in detail by Manney et al. $(2014,2017 b)$; the results are expressed as a percentage. 
To analyze the evolution of the jets in detail, the jet core locations (latitude and altitude) and windspeeds for both subtropical and polar jets are calculated for every longitude on the reanalysis grids, for 12:00UT on each day in the 35-year timeseries. These are then averaged over monthly and seasonal periods, both globally and for each season for $20^{\circ}$ longitude regions, to provide a detailed picture of the seasonal and regional changes in the timeseries of jet locations. The number of individual jets averaged for each $20^{\circ}$ longitude region depends on the longitude spacing of the reanalyses and the frequency of jet occurrence in the region; the minimum number of jets in a $20^{\circ}$ region for a season is 216, 362, 366, 399, and 548 for ERA-Interim, MERRA, MERRA-2, JRA55, and CFSR, respectively (for polar jets; the minima for subtropical jets are much larger); most regions and seasons have many more, up to over 3000 for CFSR (which has the finest longitude spacing). Thus there are sufficient jets averaged in each bin that none of the results are expected to be dominated by a few outliers.

Linear fits to the jets' latitude, altitude, and windspeed are used to examine long-term changes, which we refer to as apparent "trends", without intending any inference / speculation as to the origin of these changes. We show the $1-\sigma$ uncertainties in the slopes of the fits as one rough measure of significance - this is statistically permissive and thus is a necessary, but not sufficient, standard that must be applied before any trend could be considered robust. Significance is problematic to assess given that seasonal, interannual, and regional variations are all much larger than any potential trends. A permutation analysis (e.g., Wilks 2011, Section 5.3.4) was done that provides a measure of the significance of the slopes of individual curves: For each time period (month, season, and full year) and region $\left(20^{\circ}\right.$ longitude bins from $-180^{\circ}$ to $-160^{\circ}$ through $160^{\circ}$ to $180^{\circ}$ ), the 35 -year time series analyzed here were randomly shuffled to produce 100,000 possible arrangements of the values, and the linear regression analysis applied to those. A two-sided p-value is derived by counting how many permuted slopes are larger than those derived from the 
reanalyses, and dividing by the number of instances $(100,000)$ in the permutation distributions. While spatial or temporal autocorrelation can in general make the results of permutation tests misleading (e.g., Wilks 2011, Section 5.3.5), it is reasonable here to consider the points in the time series independent since we are applying the test individually to time series constructed separately from each regional and monthly or seasonal mean diagnostic. However, as will be seen, there can be cases where the trend from one reanalysis is significant according to that test, but is inconsistent with those in the other reanalyses. This is not too surprising, since there are documented regions/conditions for which some reanalyses are negatively affected by choices made in the data assimilation system or processing (see, e.g., Long et al. 2017), and significance in general does not imply correctness (e.g., Nicholls 2000; Nuzzo 2014). The agreement between the results for different reanalyses, as an indicator of likely consistency with the common physics represented in each model, is thus a critical indicator of the robustness of our results. If the signs of the trends for all reanalyses do not agree, the results are not considered robust regardless of how statistically significant the permutation analysis indicates those slopes to be. Agreement in the signs of the slopes among the reanalyses combined with slopes that are greater than the 1- $\sigma$ uncertainty indicates some robustness; the most robust results are those for which, in addition to these criteria, the permutation test indicates statistical significance at the $95 \%$ confidence level.

Manney et al. (2017b) provide a comprehensive comparison of the climatology of upper tropospheric and lower stratospheric jets and multiple tropopauses in the reanalyses used here. In general, the large-scale patterns seen in jet frequency distributions are similar in all the reanalyses. Notable exceptions include evidence of generally stronger tropical circulations in MERRA and MERRA-2 than in ERA-Interim vand JRA-55 (especially the equatorial easterlies associated with the Asian Summer Monsoon and the Australian monsoon, and the equatorial westerlies in SH summer downstream of the Australian monsoon), as well as slightly weaker/less persistent upper 
tropospheric jets in ERA-Interim than in MERRA-2, and stronger/more persistent jets in CFSR than in MERRA-2. These differences in strength/persistence likely reflect the lower (higher) horizontal resolution in ERA-Interim (CFSR) than in MERRA-2. MERRA and MERRA-2 also tend to show slightly higher jet altitudes in the zonal mean than do the other three reanalyses, especially in middle to high latitudes where the vertical spacing of MERRA/MERRA-2 model levels is slightly coarser than that of the other reanalyses.

\section{Results}

A global overview of jet changes during 1980 through 2014 is given in Figures 1 through 4, which show the climatological distribution of jet core locations during each season from MERRA2, along with the differences between the jet core distributions in the first (1980-1989, referred to below as "early") and last (2005-2014, referred to as "late") 10-year periods of the record. This view of frequency distributions provides direct information on the persistence and geographic variability of the jets; it also provides indirect information on jet strength since jets are identified based on a windspeed threshold. The results for the other reanalyses are generally very consistent with these, and our discussion focuses on features that are consistent among the reanalyses. These figures include all jets that are identified in the season shown rather than only those that are identified as subtropical or polar jets later in the paper. To help clarify when changes are specifically related to those jets, we have examined analogous frequency distributions constructed from the subtropical jets only (supplemental Figures S1-S4) and the polar jets only (supplemental Figures S5-S8).

Looking first at the solstice seasons, we see several notable features in the changes over the 35-year period: 
In the DJF maps (Figure 1, left side), the NH subtropical jet shifted poleward with respect to climatology between the early and late periods, as indicated by a dipole pattern of high anomalies poleward of low anomalies in the frequencies near $30^{\circ} \mathrm{N}$ from about $45^{\circ} \mathrm{W}$ to $135^{\circ} \mathrm{E}$ and over the eastern US and western Atlantic. (Note that, except if otherwise noted, west to east longitude ranges span the prime meridian, and east to west ranges span the date line.) Between about $135^{\circ} \mathrm{E}$ and $135^{\circ} \mathrm{W}$, the jet distributions are more complex (with frequent poleward excursions of the subtropical jet and/or concurrent presence of strong subtropical and polar jets, e.g., Manney et al. 2014), and there is an apparent equatorward shift of both jets (seen clearly as dipole patterns in supplementary Figures S1 and S5). Negative anomalies from about $50-60^{\circ} \mathrm{N}$ to $80^{\circ} \mathrm{N}$ with positive anomalies on the equatorward flank (see also supplementary Figure S5) suggest an equatorward shift of the polar jet, except over the north Atlantic where the patterns of changes are more complex, consistent with the varying patterns of multiple jets there (e.g., Woollings et al. 2010).

In the SH during DJF, positive anomalies flanking a negative anomaly near $45^{\circ} \mathrm{S}$ are seen from about $90^{\circ} \mathrm{W}$ to $120^{\circ} \mathrm{E}$. These changes, along with the polar jet changes shown in supplementary Figure S5, indicate an equatorward shift of the subtropical jet and a more frequent or persistent polar jet (which also may have shifted slightly poleward, see Section 3a). An additional positive anomaly is seen poleward of $60^{\circ} \mathrm{S}$ over the western Pacific (near 180 to $90^{\circ} \mathrm{W}$ ); the patterns here and in supplementary Figures S1 and S5 indicate a poleward shift of the subtropical jet, but a complex change in the preferred polar jet locations and frequency that suggests a more persistent polar jet in a narrower region near $65-70^{\circ} \mathrm{S}$. The subtropical jet over Australia extends farther west (positive anomaly centered near $90^{\circ} \mathrm{E}$ and negative anomaly from about 125 to $160^{\circ} \mathrm{E}$ ); along with a corresponding shift in equatorial easterlies in this region, this suggests a westward shift of the Australian monsoon circulation. 
The westerlies just south of the equator between $100^{\circ} \mathrm{W}$ and $160^{\circ} \mathrm{W}$, downstream of the Australian monsoon, were much more persistent in the late than in the early period (this is also apparent in the cross-section view on the RHS of Figure 1). These westerlies represent a realization of the "Gill solution", wherein convective heating results in upper-level westerlies downstream of the upper-level easterlies demarking the equatorial side of the monsoon anticyclone (Gill 1980; Sardeshmukh and Hoskins 1988). This pattern is associated with the Walker circulation, which strengthens during La Niña periods (e.g., Julian and Chervin 1978; Bayr et al. 2014). During DJF, the early period considered here was more dominated by El Niño than the late period (mean Multivariate ENSO Index of 0.30 and -0.27 , respectively); thus, more persistent westerlies in this region is consistent with differences in ENSO conditions during the two periods. The Australian monsoon easterlies were also more persistent in the late period, consistent with this view.

The poleward shift of the NH subtropical jet seen over a broad longitude range is weakly apparent in the zonal mean (Figure 1 and supplemental Figure S1, right side). The cross-section shows an upward shift of the NH winter jets at all latitudes, accompanied by less persistent high-latitude jets (north of $\sim 50^{\circ}$ ). In the $\mathrm{SH}$, a single jet near $50^{\circ} \mathrm{S}$ appears to dominate the zonal mean picture; however, Figures S1 and S5 show that to be a superposition of narrowly separated polar and subtropical jets, with the polar jet showing increased persistence and the subtropical jet complex changes reflecting the large variations in position of that jet with longitude.

In JJA (Figure 2; also supplemental Figures S2 and S6), the NH subtropical jet shows a a poleward shift over Asia, but the most striking difference from climatology is the altitude increase of all $\mathrm{NH}$ jets poleward of about $40^{\circ} \mathrm{N}$. As was the case in DJF, an equatorward shift of the polar jet is indicated, with less frequent or persistent jets north of $\sim 60^{\circ} \mathrm{N}$. The $\mathrm{SH}$ wintertime patterns are more difficult to interpret because of the persistence of at least two strong zonal jets, but the patterns in both the maps and cross-sections (as well as in supplemental Figures S2 and S6) are 
consistent with a poleward shift of both jets except in the longitude region from about $130^{\circ} \mathrm{W}$ to $45^{\circ} \mathrm{W}$. The $\mathrm{SH}$ polar jet is prominent from 0 to $180^{\circ} \mathrm{E}$ in JJA, and is shifted poleward with respect to the early years. The cross-sections (see also those in Figures S2 and S6) suggest a poleward shift and greater persistence of the subtropical jet, and a downward shift of the polar jet, which has two prefered latitude locations over many longitude regions. The anomalies suggest a larger Asian monsoon circulation in that the easterlies bounding the equatorial edge of that circulation shifted equatorward and the westerlies bounding the mid-latitude edge shifted poleward. Stronger positive than negative anomalies near the western edge suggest a slight westward shift of this monsoon circulation.

The equinox seasons show both similarities to and difference from the solstice seasons:

The SH anomalies in MAM (Figure 3; supplemental Figures S3 and S7) are qualitatively similar to those in DJF. The positive anomalies near $30^{\circ}$ and negative ones near $40^{\circ} \mathrm{S}$ over South America and the Atlantic indicate an equatorward shift of the subtropical jet. In the NH in MAM, the anomalies show quite different patterns than during either solstice season, suggesting an equatorward rather than a poleward shift of the subtropical jet over northern Africa and Asia, though a poleward shift is still seen over the western North America and most of the Atlantic; the subtropical jet over the eastern Pacific (see Figure S3) shifts towards two preferred positions. Greater rather than less (as in DJF) persistence of the high-latitude (poleward of about $60^{\circ} \mathrm{N}$ ) jets is seen in some longitude regions, but Figure S7 still indicates an equatorward shift of the polar jet in most regions.

In SON, the SH anomalies are similar to, but weaker than, those in JJA, except over the eastern Pacific, where changes are more pronounced. The NH anomalies show a high-low-high pattern over Asia that could arise from various changes, including (as supported below) the $\mathrm{NH}$ subtropical and polar jets shifting closer together in this longitude region; a significant negative anomaly 
is seen associated with the strong northeastward tilting jet over the eastern US and Atlantic, in contrast to a strong positive one associated with that jet in DJF and weaker anomalies of both signs in JJA and SON.

The maps and cross-sections provide a broad qualitative picture of the long-term evolution of the jet frequency distributions. Because of the large regional and seasonal variability, a more focused set of diagnostics is needed to quantify these long-term changes. In the following sections, we use jet location and strength diagnostics to explore in detail the regional and seasonal variations in the subtropical and polar jets separately in each hemisphere.

\section{a. Subtropical Jet Time Series and Tropical Width}

Figures 5 and 6 show time series of the subtropical jet core latitude and altitude, respectively, averaged around the globe and over each solstice season (similar plots for the equinox seasons are shown in supplementary Figures S15 and S16). The latitudes of the subtropical jets vary among the reanalyses by up to over a degree in the $\mathrm{NH}$ and nearly three degrees in the $\mathrm{SH}$, with CSFR (ERAInterim) subtropical jets located most (least) equatorward in both hemispheres. The altitudes vary by up to $\sim 0.3(0.6) \mathrm{km}$ in the $\mathrm{NH}(\mathrm{SH})$.

Interannual variability is much larger than any apparent trends in all cases. In this zonally averaged view, most apparent trends are either clearly insignificant (that is, don't even exceed the $1-\sigma$ uncertainty) or disagree among the reanalyses. Robust trends are seen in a few cases: $\mathrm{NH}$ subtropical jet altitudes increase very consistently for all reanalyses in all seasons except MAM (when there is consistently little or no altitude change), and SH subtropical jets shift poleward in JJA (NH jets also shift poleward in JJA, but the uncertainties are large, so the change is not signficant). The largest inconsistencies among the reanalyses are in the $\mathrm{SH}$, where the latitude trends vary widely (often even in sign) except in JJA, and altitude trends vary widely in all seasons. 
Jet core windspeeds were also examined (not shown), and indicate a robust decrease in the $\mathrm{NH}$ in JJA over the 35-year period; in the SH, windspeed changes are inconsistent among the reanalyses. The changes illustrated in these timeseries are summarized in the following figures as a function of month/season and longitude by plotting bars indicating the slope of the fits shown above and the $1-\sigma$ uncertainty in their slopes. Triangles point to the bars for which the change was significant at the $95 \%$ confidence level in the permutation test.

Figure 4 summarizes the seasonal variations in subtropical jet latitude, altitude, and windspeed tendencies averaged over all longitudes. In general, the zonally averaged latitude changes are robust (in that the slopes exceed the $1-\sigma$ uncertainty and agree among the reanalyses) only in a few months, and less so when averaged over a season or annually. The NH subtropical jet latitude shows a robust poleward shift in February and September, and a consistent (i.e., all reanallyses' slopes have the same sign, but not all exceed the $1-\sigma$ uncertainty) equatorward shift in November and December; seasonal and annual shifts are not significant. Only the September shift is significant in the permutation analysis.

The SH subtropical jet shows consistent poleward shifts in June through October, and in JJA and SON; the shifts in May are signficant at the $95 \%$ level. Consistent (robust and signficant) equatorward shifts are seen in April (May). In combination, the width of the tropics, as measured by the $\mathrm{NH} / \mathrm{SH}$ subtropical jet separation, is positive (widening tropics) in June through October, and in JJA and SON, while it is negative (narrowing tropics) in April, May, November, and December. Only the September increase is signficant at the $95 \%$ level in all reanalyses, though the decrease in December is significant at the $90 \%$ or $95 \%$ level in several reanalyses (see Supplementary Figure S9). During months when the reanalyses do not agree, CSFR often shows the opposite sign to the other reanalyses. 
The jet altitude changes seen in Figure 4 are mostly robust, with consistent increases in $\mathrm{NH}$ subtropical jet altitude in the NH except in March, May, and MAM, when changes are near zero; largest increases are seen in November, December, and DJF, and these and the annual increase are significant at the $95 \%$ level in the permutation analysis. In the $\mathrm{SH}$, robust (and often significant) positive changes are seen in April, May, and December; annual mean SH altitudes also increase, except in CSFR. The patterns of altitude shifts vary strongly by region (see below), and the appearance of abrupt shifts from postive to negative changes (e.g., SH altitudes in March and April) reflects month to month changes in the regional patterns and which of them dominate the zonal mean. Windspeed changes are small $\left(< \pm 0.05 \mathrm{~ms}^{-1} / \mathrm{year}\right)$ and variable from month to month. Robust windspeed increases are seen in January, April, and May in the NH, with decreases in March and June (the last is signficant at the 95\% level). SH windspeed changes are not robust, but tend to be positive in most seasons.

Figures 8 and 9 show the trends as a function of longitude for DJF and JJA, respectively (the corresponding equinox season plots are shown in Supplemental Figures S17 and 18). The large longitudinal variations help explain why the global trends shown above are often small. In DJF (Figure 8) in the NH, a robust equatorward jet shift is seen over the Pacific, with large changes (significant at the $95 \%$ level) in the eastern Pacific $\left(\sim 120^{\circ} \mathrm{W}\right.$ to $\left.160^{\circ} \mathrm{W}\right)$; there is a robust and significant poleward shift from about $40^{\circ} \mathrm{W}$ to $140^{\circ} \mathrm{E}$ (from the eastern Atlantic across Eurasia). In the SH, a poleward shift is seen near the dateline, and distinct equatorward shifts from about $140^{\circ} \mathrm{W}$ to $40^{\circ} \mathrm{W}$, and about $60^{\circ} \mathrm{E}$ to $100^{\circ} \mathrm{E}$, except in CFSR, which shows large poleward shifts in these regions that are sometimes significant at the 90 or $95 \%$ level in the permutation analysis (see also Supplementary Figure S10). Opposite subtropical jet latitude shifts in the two hemispheres thus often lead to insignificant changes in tropical width as measured by the distance between the $\mathrm{NH}$ and SH subtropical jets. A significant negative change (narrowing tropics) is seen from 
about $160^{\circ} \mathrm{W}$ to $40^{\circ} \mathrm{W}$ in most of the reanalyses, and a mostly robust (and significant in some reanalyses) positive shift (widening) from about $20^{\circ} \mathrm{W}$ to $40^{\circ} \mathrm{E}$. Over Asia and South America, the large inconsistency between CFSR and the other reanalyses precludes identification of any robust trends.

Altitude shifts in DJF are consistently positive, except in the SH near the date line, and in both hemispheres near the Greenwich meridian, where the changes are very small; changes in the western Pacific are significant in the permutation analysis. A substantial increase $(0.10$ to 0.15 $\mathrm{m} / \mathrm{s} /$ year $)$ in windspeed is seen in the $\mathrm{NH}$ from western North America $\left(\sim 120^{\circ} \mathrm{W}\right)$ all the way across Asia (to $\sim 140^{\circ} \mathrm{E}$ ), with a similarly strong decrease in windspeed over the central to eastern Pacific. Increases/decreases in windspeed are correlated with increases/decreases in jet latitude, suggesting that angular momentum is largely conserved on the temporal and spatial scales of these changes (see, e.g., Martius 2014). Windspeed changes are smaller in the SH, with robust positive changes over the western Pacific and consistent negative changes over the Indian Ocean.

In JJA (Figure 9) the subtropical jet latitude shifts are also highly variable with longitude, with robust poleward shifts in the $\mathrm{NH}$ over Asia (near $\sim 30^{\circ} \mathrm{E}$ and between $\sim 80$ and $120^{\circ} \mathrm{E}$ ); a consistent equatorward shift in the western Pacific $\left(\sim 180-160^{\circ} \mathrm{W}\right)$; and very small or inconsistent shifts elsewhere. In the SH, the subtropical jet shifts poleward from about the Greenwich meridian eastward to about $140^{\circ} \mathrm{W}$; equatorward in the eastern Pacific; and shows small/inconsistent shifts over the Atlantic. The combined shifts in the $\mathrm{NH}$ and $\mathrm{SH}$ result in a widening of the tropics across most of the 0 to $120^{\circ} \mathrm{E}$ region, and over the eastern Pacific; these changes are significant at the $95 \%$ level in the $80^{\circ} \mathrm{E}$ to $120^{\circ} \mathrm{E}$ longitude bands. Subtropical jet altitude shifts in the $\mathrm{NH}$ are consistently positive except from about 80 to $120^{\circ} \mathrm{E}$, and are significant at the 90-95\% level (see also supplementary Figure S11) from about $120^{\circ} \mathrm{W}$ to $40^{\circ} \mathrm{W}$. SH altitude shifts are generally small and often inconsistent among the reanalyses. Supplementary Figure S17 shows a similar but more robust 
pattern of SH jet altitude shifts in MAM, and examination of individual months shows that the upward shift from about 100W to 80E is the dominant pattern in April and May, while the downward shifts over Australia and the Pacific dominate in March - thus changes in regional patterns result in the transition from downward to upward altitude shift from March to April noted in Figure 4. $\mathrm{NH}$ windspeed changes are small, and negative except over the Atlantic. Relatively large $(0.10$ to $0.15 \mathrm{~m} / \mathrm{s} /$ year) consistent (and often significant at the 95\% level) windspeed increases are seen in the $\mathrm{SH}$ from about $80^{\circ} \mathrm{W}$ to $60^{\circ} \mathrm{E}$.

The above results highlight the strong regional and seasonal variations in the subtropical jets' positions, which argues that there is no single consistent global and/or annually averaged trend. In fact, our results show that averaging over different regional and seasonal regimes obscures substantial regional and seasonal trends. In the following, we examine similar diagnostics for the polar, or eddy-driven, jets.

\section{b. Polar Jet Time Series and Interjet Relationships}

Figures 10 and 11 show timeseries of polar jet latitude and altitude, respectively, during the solstice seasons (the equinox seasons are shown in Supplementary Figures S21 and S22). Like the subtropical jet, interannual variations in polar jet positions are much larger than any overall trend. Unlike the subtropical jet, the polar jet latitudes and altitudes show distinct trends that are usually fairly consistent among the reanalyses. A strong equatorward shift is seen in the NH polar jet latitude in DJF, MAM, and JJA. The SH polar jet shows a small poleward shift in DJF and JJA and a small equatorward shift in MAM except in CFSR. Increases in polar jet altitude are seen in the NH in all seasons and in the SH in DJF and MAM; SH altitude trends are inconsistent among the reanalyses in JJA and SON. Windspeed changes (not shown) are small in both hemispheres, showing small but consistent increases (decreases) in the NH in DJF and MAM (JJA). Comparing 
Figures 10 and 5 indicates that the typical jet separation is about $16-18^{\circ}$ in the $\mathrm{SH}, 25-30^{\circ}$ in $\mathrm{NH}$ winter, and $20-22^{\circ}$ in $\mathrm{NH}$ summer; the subtropical and polar jets are thus fairly well-separated in latitude, but changes in jet separation discussed below may be expected to reflect changing roles of eddy and radiative processes in driving the jets (see, e.g., Lee and Kim 2003; Martius 2014).

Global monthly, seasonal, and annual changes in the polar jets are summarized in Figure 12. The NH polar jet shows a robust equatorward shift through three seasons, except in SON, and that shift is significant in the permutation analysis in February, DJF, JJA, and the annual mean (see also Supplementary Figure S12). Combined with the subtropical jet changes described above, this results in a decrease in the polar/subtropical jet separation in January through September (with the strongest decrease in February), and a robust increase only in November. The NH polar jet altitude increases in all months and seasons. NH polar jet windspeed changes are small, but are significantly positive (negative) in February and March (June, August, October, and JJA) (see also Supplementary Figure S12).

The SH polar jet latitude shifts are small and vary in sign from month to month during much of the year. Consistent poleward shifts are seen only in February, July, August, and JJA, and only the shift in February is significant in the permutation analysis. The SH polar/subtropical jet separation increases in February, April, May, and December, and decreases significantly in September and SON. The SH polar jet altitude generally increases, except in MERRA-2 in May through October. Significant increases in SH polar jet windspeed are seen in January through May, DJF, and MAM. As was the case for the subtropical jet, Figures 13 (for DJF) and 14 (for JJA) indicate strong regional variations in polar jet trends that account for the lack of a clear signal of zonally averaged changes at many times:

In DJF (Figure 13), the NH polar jet latitude decreases strongly from just west of the Greenwich meridian across Europe, Asia, and the Pacific to about $140^{\circ} \mathrm{W}$ (in many regions these changes are 
significant in the permutation analysis at the $90-95 \%$ level, see also Supplementary Figure S13). With the subtropical jet changes, this means that the polar/subtropical jet separation decreases from the eastern Atlantic to the central Pacific, and shows a consistent (but small) increase only between about $40^{\circ} \mathrm{W}$ and $60^{\circ} \mathrm{W}$. The $\mathrm{NH}$ polar jet altitude increases at all longitudes, and is particularly significant in the permutation analysis over the eastern Pacific. NH polar jet windspeeds change significantly over most regions, strengthening over the Pacific and weakening over the eastern Atlantic, Europe, and most of Asia. In the SH in DJF, robust poleward shifts of the polar jet are seen from about $100^{\circ} \mathrm{W}$ to about $120^{\circ} \mathrm{E}$. The SH subtropical jet (Figure 8,9$)$ generally shifts poleward less than the polar jet, leading to a widening of the inter-jet distance from about $140^{\circ} \mathrm{W}$ to $120^{\circ} \mathrm{E}$ in DJF.

The pattern of polar jet changes is similar during most of the year: Changes in JJA (Figure 14) are similar to, but generally more significant than, those in DJF, with larger magnitude altitude changes. There is a narrower longitude region of poleward jet shifts in the $\mathrm{SH}$, resulting in less extensive widening of SH subtropical/polar jet separation in JJA, extending only from about $80^{\circ} \mathrm{W}$ to $40^{\circ} \mathrm{E}$. NH JJA windspeed changes are typically smaller than those in DJF, and are mostly negative except between $100^{\circ} \mathrm{E}$ and $180^{\circ} \mathrm{E}$; the $\mathrm{SH}$ shows more robust windspeed decreases from about $20^{\circ} \mathrm{E}$ to $100^{\circ} \mathrm{E}$. In MAM (supplementary Figure S23), the $\mathrm{NH}$ polar jet shifts equatorward from the eastern Pacific across to India. NH jet altitudes robustly increase from the $180^{\circ} \mathrm{W}$ to $80 \mathrm{E}$, and windspeeds show mostly consistent increases from $140^{\circ} \mathrm{W}$ to $60^{\circ} \mathrm{E}$. In the $\mathrm{SH}$, MAM polar jet latitude trends follow the same pattern as in JJA, with small windspeed increases and mostly robust altitude increases that are often signficant at the $95 \%$ level for all longitudes. SH jet latitudes in turn only show robust (and significant) negative changes from 160W to 40W. Supplementary Figure S24 indicates that SON changes in the $\mathrm{NH}(\mathrm{SH})$ are qualitatively very similar to those in the $\mathrm{NH}(\mathrm{SH})$ in DJF (JJA), but generally smaller and less robust for all diagnostics. 
The polar jets in both hemispheres thus show stronger and more consistent changes than the subtropical jets, but the variability still highlights the importance of regional and seasonal differences in the patterns of long-term changes.

\section{Discussion and Conclusions}

Interannual and long-term variations in upper tropospheric jet locations and strength are evaluated by characterizing individual jet core locations (Manney et al. 2011), providing a detailed picture of regional and seasonal differences in long-term changes using a 3D daily, rather than a zonal and/or monthly mean, characterization of the jets. We examined changes in the subtropical and polar (aka "eddy-driven") jets separately, and analyzed five high-resolution reanalyses to assess the robustness of changes.

Maps and cross-sections of differences between jet frequency distributions in the first and last ten years of the 35-year study period show a pattern of changes that is generally consistent among the five reanalyses. The subtropical jets in both hemispheres shifted poleward and upward in many regions except during MAM, when equatorward shifts dominated in both hemispheres. In the NH over the eastern Pacific, the subtropical jet shifted equatorward in winter. NH high latitude jet frequency changes are largely consistent with an equatorward shift of the polar jet. Jet altitudes appear to have increased in most regions and seasons. With regard to the tropical circulations, Australian monsoon easterlies and associated Walker circulation westerlies became more persistent over the 35-year period, and the Asian summer monsoon increased in size and shifted slightly westward.

Examination of differences between the first ten years and the second to last ten years (not shown) suggest that many of the stronger changes are cumulative over the study period. However, modes of natural variability such as ENSO also show differences over the 35-year period. In DJF, 
the early period was dominated more by El Niño and the late period more by La Niña. As shown by Manney et al. (2017a, in preparation), the changes in the tropical jets are consistent with variations in the Walker circulation, with more persistent equatorial eastern Pacific westerlies downstream of the Australian monsoon in periods with strong La Niñas. The poleward shift of the NH subtropical jet in DJF also appears consistent with the shifts seen in El Niño vs La Niña periods, and with previous results relating ENSO to jet shifts (Langford 1999; Lin et al. 2014; Bai et al. 2016, and references therein). JJA was either dominated by El Niño or near neutral throughout the 35-year period of study, suggesting that the anomalies in JJA are largely the result of long term changes (such as climate change or ozone depletion) that are not closely linked to ENSO. The equinox seasons are more dominated by El Niño in the early period than in the late period; however, the patterns of early/late changes found here here are not obviously consistent with the variations seen in different ENSO phases, again suggesting other controlling mechanisms. Even in DJF when some patterns are consistent with expected ENSO-related changes, this does not preclude those changes being related to climate change impacts that may themselves be correlated with ENSO changes. Several other modes of natural variability such as the North Atlantic Oscillation, Arctic Oscillation, Southern Annular Mode, Quasi-Biennial oscillation, Pacific Decadal Oscillation, and Madden-Julian Oscillation may also be associated with changes in the in the upper tropospheric jets on decadal or longer timescales (Thompson et al. 2000, 2011; Overland and Wang 2005; Woollings et al. 2010, 2014; Lucas and Nguyen 2015, and references therein) and thus may be important to consider in interpreting the physical causes of the observed changes.

Our results highlight strong seasonal, regional, and hemispheric differences in the trends in upper tropospheric jets seen in reanalyses. When zonally averaged, only a few seasons/regions show robust changes in subtropical or polar jet locations and/or windspeeds. The mean values for jet core latitude, altitude, and windspeed for a month or season in a given year fold together 
very large regional, interannual, and day-to-day variations. In addition, some reanalyses have known discontinuities or shortcomings that affect detection of trends. Thus, assessment of the statistical significance of apparent trends in individual reanalyses on its own does not provide much information on the degree of certainty in atmospheric trends, and consistency between the reanalysis datasets is a critical part of assessing the robustness of the trends. Robust trends are identified where slopes exceed the $1-\sigma$ range of uncertainty and agree among the reanalyses; a permutation analysis of the trends for individual reanalyses provides a measure of how statistically significant those trends are. Figures 15 and 16 summarize these three measures of robustness and significance by region and season for the subtropical and polar jets, respectively. The most robust subtropical jet changes are:

- The NH subtropical jet shifts poleward in winter over Asia, and in fall over the western Pacific; a strong equatorward shift is seen in winter over the eastern Pacific.

- The SH subtropical jet shows a poleward shift in most seasons (except DJF) over the eastern Pacific, and over Africa in JJA and SON. It shows a strong equatorward shift in MAM over South America, the Atlantic, and western Africa.

- Consistent with the above changes, tropical widening is seen during JJA, SON, and DJF across Africa, and during JJA over Asia and the western Pacific. In contrast, significant narrowing of the tropics is seen in DJF from the central Pacific across North America and the western Atlantic.

- NH subtropical jet altitudes increased in all seasons except MAM, with most robust changes over the eastern Pacific in DJF, and over the US and western Atlantic in JJA and SON. 
- SH jet altitudes tended to increase, but only show robust changes in MAM over the Atlantic and Africa, and in SON over the eastern Pacific, and across North America to the western Atlantic.

- Regions of robust and significant NH windspeed increases are seen over the Atlantic in DJF and MAM, over central Asia in DJF, and over eastern Asia in MAM. A robust windspeed decrease is seen in over most of the Pacific DJF and over the western Pacific in JJA.

- SH windspeeds show robust and significant increases in JJA and SON over Africa and the western Pacific, as well as over South America and the Atlantic in JJA and over eastern Australia in MAM.

The most robust changes in the polar jet are:

- The NH polar jet moved equatorward in all seasons over much of the globe, except over eastern North America and the western Atlantic, where the shift varies with season and is sometimes poleward.

- The SH polar jet shifted poleward during summer and winter (and, less robustly, during fall and spring) across the Atlantic and Indian Ocean, but shifted equatorward over most of the Pacific except during DJF.

- NH polar jet altitudes increased significantly in all seasons around the globe, except over eastern Asia and the western Pacific in MAM.

- SH polar jet altitudes increased over the eastern Pacific in DJF and MAM, but showed inconsistent shifts among the reanalyses in other seasons/regions. 
- NH polar jet windspeeds decreased over Europe and central Asia in fall and winter, and over North America and the Atlantic in summer. Windspeeds increased over the Pacific in DJF and over the eastern Pacific and western North America in MAM.

- SH polar jet windspeeds increased from the western Pacific across South America, the Atlantic, and Africa in summer and fall.

In regions and seasons where trends are strong, and in nearly all cases in the $\mathrm{NH}$, the reanalyses usually show consistent results, supporting the robustness of the jet trends in these regions. The signs of the trends are typically in the same direction (although the magnitudes can differ considerably, as do the $1-\sigma$ ranges of uncertainties and the significance indicated by a permutation analysis). Notable exceptions to this are poleward rather than equatorward SH subtropical jet latitude trends in CSFR during DJF and decreasing rather than increasing altitude trends in CFSR during JJA. MERRA-2 also shows decreasing rather than increasing polar SH jet altitudes in JJA and SON in contrast to the other reanalyses.

While some evidence is seen of the poleward and upward shift of the subtropical jet that is expected based on model simulations (Hartmann et al. 2013, and references therein), the presence and significance of these changes depends on region and season. From these evaluations it follows that tropical widening is clearly not a zonal feature either, perhaps consistent with the lack of consensus in observational studies based on varying datasets and methods largely based on zonal means (e.g., Seidel et al. 2008; Birner et al. 2014; Davis and Birner 2017). In particular, the strong equatorward shift in the eastern Pacific off the west coast of North America has not been widely recognized and is largely responsible for the lack of a robust poleward shift of the subtropical jet (and hence widening of the tropics) in zonal mean evaluations. On the other hand, the robust poleward shift of the NH subtropical jet over Africa in all seasons except NH spring 
(together with the poleward shift of the SH subtropical jet in JJA and SON) leads to a clear signal of regional expansion, which is expected to be associated with drying of the subtropics and sub-Saharan region.

As noted in the introduction, there is considerable disagreement over observed and expected shifts in the NH polar jets; our results of a consistent equatorward shift in most regions are generally consistent with those of Barton and Ellis (2009) and Strong and Davis (2007). Several previous studies suggest a poleward shift of the SH polar jet in DJF and MAM that has been attributed to effects of ozone loss (see, e.g., Grise et al. 2013; Peña-Ortiz et al. 2013; Waugh et al. 2015); our results indeed show a poleward shift in DJF over many regions (as well as a similar shift in JJA that has not been widely reported, and less robust shifts in MAM and SON in the same direction and regions), but the equatorward shift in all seasons over the Pacific highlights the necessity of considering regional and seasonal variations. The strong regional and seasonal variability again argues that there is no single consistent global and/or annually averaged trend. In fact, our results show that averaging over different regional and seasonal regimes, and not clearly distinguishing between the subtropical and polar jets, can obscure significant regional and seasonal trends.

The separate analysis of NH subtropical and polar jets supports previous results and theoretical arguments that have suggested that, while the subtropical jet moves poleward, the NH polar jet weakens and moves equatorward in a warming climate. The changes in the polar jet may be a consequence of Arctic amplification, for which several mechanisms have been proposed (see Hoskins and Woollings 2015, and references therein). Distinguishing between the subtropical and polar jets separates changes that may be due to different mechanisms and thus have different regional and seasonal variations.

Our results from multiple reanalyses can not only serve as an observationally-based reference for model comparisons over the past $\sim 30$ years, but also have farther-reaching implications for 
the evaluation of jet changes in global climate models (such as those used in CMIP). The spatial and temporal differences in jet behavior, and the mechanisms driving these changes, must be considered. Zonally, annually, or vertically averaged jet distributions span multiple regimes, which can obscure the true changes. Evaluations should hence focus on seasonally, zonally, and vertically resolved behavior. Characterizing jets using monthly mean wind data (such as those available for CMIP results) will thus provide much less complete information than using daily data. The availability of high-quality reanalyses, and ongoing comprehensive evaluation of these reanalyses (e.g., Fujiwara et al. 2017; Long et al. 2017; Manney et al. 2017b, and references therein), allows us to assess the robustness of features that are not directly observable, such as jet shifts, by analyzing the consistency among the reanalyses.

This study thus highlights the need to approach the analysis of trends in jet-related variables, and the mechanisms that drive those changes, in a more process-oriented way and with a focus on regional and seasonal signatures of the climate-induced changes that are most relevant for future climate change adaption and mitigation decisions.

Acknowledgments. We thank the MLS team at JPL, especially Luis F. Millán Valle, Brian W. Knosp, Alyn Lambert, William H. Daffer, Ryan A. Fuller, and Nathaniel J. Livesey, for scientific, data management/processing, and computational support; NASA's GMAO, ECMWF, JMA, and NCEP for providing their assimilated data products; and Krzysztof Wargan for advice on MERRA and MERRA-2 quality and usage. Thanks to Thando Ndarana for a helpful/interesting discussion of our Southern Hemisphere results; to Zachary D. Lawrence for help with statistical analysis and numerous helpful discussions and suggestions (i.e., LTUAE); and to the three anonymous referees for their very helpful comments. The datasets used are publicly available, as follows:

- MERRA-2: https://disc.sci.gsfc.nasa.gov/uui/datasets?keywords=\%22MERRA-2\%22 
- MERRA: https://disc.sci.gsfc.nasa.gov/uui/datasets?keywords=\%22MERRA\%22

- ERA-I: http://apps.ecmwf.int/datasets/

- JRA-55: Through NCAR RDA at http://dx.doi.org/10.5065/D6HH6H41

- CFSR, model level data: Available upon request from Karen $\mathrm{H}$ Rosenlof (karen.h.rosenlof@noaa.gov)

- JETPAC products: Contact Gloria L Manney (manney@nwra.com)

\section{References}

Arblaster, J., G. Meehl, and D. Karoly, 2011: Future climate change in the Southern Hemisphere: Competing effects of ozone and greenhouse gases. Geophys. Res. Lett., 38 (2).

Archer, C. L. and K. Caldeira, 2008: Historical trends in the jet streams. Geophys. Res. Lett., 35, L08803, doi:10.1029/2008GL033614.

Bai, K., N.-B. Chang, and W. Gao, 2016: Quantification of relative contribution of Antarctic ozone depletion to increased austral extratropical precipitation during 19792013. J. Geophys. Res., 121, 1459-1474, doi:10.1002/2015JD024247, URL http://dx.doi.org/10.1002/ $2015 J D 024247$.

Baldwin, M. P., M. Dameris, and T. G. Shepherd, 2007: How will the stratosphere affect climate change, Science, in press, 2007.

Barnes, E. A. and L. Polvani, 2013: Response of the midlatitude jets, and of their variability, to increased greenhouse gases in the CMIP5 models. J. Clim., 26 (18), 7117-7135.

Barnes, E. A. and L. M. Polvani, 2015: CMIP5 projections of Arctic amplification, of the North American/North Atlantic circulation, and of their relationship. J. Clim., 28 (13), 5254-5271. 
Barnes, E. A. and J. A. Screen, 2015: The impact of Arctic warming on the midlatitude jet-stream: Can it? has it? will it? Wiley Interdisciplinary Reviews: Climate Change, 6 (3), 277-286.

Barton, N. P. and A. W. Ellis, 2009: Variability in wintertime position and strength of the North Pacific jet stream as represented by re-analysis data. Int. J. Climatol., 29, 851-862.

Bayr, T., D. Dommenget, T. Martin, and S. B. Power, 2014: The eastward shift of the Walker Circulation in response to global warming and its relationship to ENSO variability. Clim. Dyn., 43 (9-10), 2747-2763.

Birner, T., S. M. Davis, and D. J. Seidel, 2014: Earths tropical belt. Phys. Today, 67 (12), 38.

Bosilovich, M., et al., 2015: MERRA-2: Initial evaluation of the climate. Series on Global Modeling and Data Assimilation, NASA/TM2015-104606, Vol. 43, NASA.

Butler, A. H., D. W. Thompson, and R. Heikes, 2010: The steady-state atmospheric circulation response to climate change-like thermal forcings in a simple general circulation model. J. Clim., 23 (13), 3474-3496.

Cohen, J., et al., 2014: Recent Arctic amplification and extreme mid-latitude weather. Nature Geosci., 7 (9), 627-637.

Compo, G. P., et al., 2011: The twentieth century reanalysis project. Q. J. Roy. Meteorol. Soc., 137 (654), $1-28$.

Davis, N. and T. Birner, 2017: On the discrepancies in tropical belt expansion between reanalyses and climate models and among tropical belt width metrics. J. Clim., 30, 1211-1231.

Davis, S. M. and K. H. Rosenlof, 2012: A multidiagnostic intercomparison of tropical-width time series using reanalysis and satellite observations. J. Clim., 25, 1061-1078. 
Davis, S. M., et al., 2017: Assessment of upper tropospheric and stratospheric water vapour and ozone in reanalyses. Atmos. Chem. Phys. Disc., submitted.

Dee, D. P., et al., 2011: The ERA-Interim reanalysis: configuration and performance of the data assimilation system. Q. J. R. Meteorol. Soc., 137, 553-597.

Delworth, T. L. and F. Zeng, 2014: Regional rainfall decline in Australia attributed to anthropogenic greenhouse gases and ozone levels. Nature Geosci., 7, 583-587.

Dragani, R., 2011: On the quality of the ERA-Interim ozone reanalyses: comparisons with satellite data. Q. J. R. Meteorol. Soc., 137, 1312-1326.

Ebita, A. et al., 2011: The Japanese 55-year Reanalysis "JRA-55": An interim report. SOLA, 7, $149-152$.

Fujiwara, M., et al., 2017: Introduction to the SPARC Reanalysis Intercomparison Project (SRIP) and overview of the reanalysis systems. Atmos. Chem. Phys., 17, 1417-1452, doi:10.5194/ acp-17-1417-2017, URL www . atmos-chem-phys .net/17/1417/2017/.

Garfinkel, C. I., D. W. Waugh, and E. P. Gerber, 2013: The effect of tropospheric jet latitude on coupling between the stratospheric polar vortex and the troposphere. J. Clim., 26, 2077-2095.

Garfinkel, C. I., D. W. Waugh, and L. M. Polvani, 2015: Recent Hadley cell expansion: The role of internal atmospheric variability in reconciling modeled and observed trends. Geophys. Res. Lett., 42 (24).

Gelaro, R. et al., 2017: The Modern-Era Retrospective Analysis for Research and Applications, Version-2 (MERRA-2). J. Clim., doi:doi:10.1175/JCLI-D-16-0758.1, in press.

Gill, A. E., 1980: Some simple solutions for heat-induced tropical circulation. Q. J. R. Meteorol. Soc., 106, 447-462. 
Global Modeling and Assimilation Office (GMAO), 2015: Merra-2 inst3_3d_asm_nv: 3d, 3hourly,instantaneous, model-level, assimilation, assimilated meteorological fields v5.12.4, greenbelt, md, usa, goddard earth sciences data and information services center (ges disc), accessed 1 november 2015. doi:10.5067/WWQSXQ8IVFW8.

Gómara, I., J. G. Pinto, T. Woollings, G. Masato, P. Zurita-Gotor, and B. Rodríguez-Fonseca, 2014: Rossby wave-breaking analysis of explosive cyclones in the Euro-Atlantic sector. Q. J. R. Meteorol. Soc., 140, 738-753, doi:10.1002/qj.2190, URL http://dx.doi.org/10.1002/qj . 2190.

Grise, K. M., L. M. Polvani, G. Tselioudis, Y. Wu, and M. D. Zelinka, 2013: The ozone hole indirect effect: Cloud-radiative anomalies accompanying the poleward shift of the eddy-driven jet in the Southern Hemisphere. Geophys. Res. Lett., 40, 1-5, doi:10.1002/grl.50675.

Harnik, N., C. I. Garfinkel, and O. Lachmy, 2016: The influence of jet stream regime on extreme weather events. in "Dynamics and Predictability of Large-Scale, High-Impact Weather and Climate Events", 2, 79-94.

Hartmann, et al., 2013: Climate Change 2013: The Physical Science Basis. Contribution of Working Group I to the Fifth Assessment Report of the Intergovernmental Panel on Climate Change, chap. Observations: Atmosphere and Surface. Cambridge University Press, Cambridge, United Kingdom and New York, NY, USA.

Held, I. M., 1993: Large-scale dynamics and global warming. Bull. Am. Meteor. Soc., 74, 228-241.

Held, I. M. and B. J. Hoskins, 1985: Large-scale eddies and the general circulation of the troposphere. Adv. Geophys., 28, 3-31. 
Held, I. M. and A. Y. Hou, 1980: Nonlinear axially symmetric circulations in a nearly inviscid atmosphere. J. Atmos. Sci., 37, 515-533.

Held, I. M., M. Ting, and H. Wang, 2002: Northern winter stationary waves: Theory and modeling. J. Clim., 15, 2125-2144.

Homeyer, C., K. P. Bowman, and L. L. Pan, 2010: Extratropical tropopause transition layer characteristics from high-resolution sounding data. J. Geophys. Res., 115, D13108, doi: 10.1029/2009JD013664.

Hoskins, B. and T. Woollings, 2015: Persistent extratropical regimes and climate extremes. Current Climate Change Reports, 1 (3), 115-124, doi:10.1007/s40641-015-0020-8, URL http: //dx.doi.org/10.1007/s40641-015-0020-8.

Hoskins, B. J. and P. J. Valdes, 1990: On the existence of storm tracks. J. Atmos. Sci., 47, 18541864.

Huang, D.-Q., J. Zhu, Y.-C. Zhang, J. Wang, and X.-Y. Kuang, 2015: The impact of the East Asian subtropical jet and polar front jet on the frequency of spring persistent rainfall over Southern China in 1997-2011. J. Clim., 28, 6054-6066, doi:10.1175/JCLI-D-14-00641.1.

Hudson, R. D., 2012: Measurements of the movement of the jet streams at mid-latitudes, in the Northern and Southern Hemispheres, 1979 to 2010. Atmos. Chem. Phys., 12, 7797-7808.

Julian, P. and R. Chervin, 1978: A study of the Southern Oscillation and Walker circulation phenomenon. Mon. Weather Rev., 106, 1433-1451.

Kang, S. M., L. M. Polvani, J. C. Fyfe, and M. Sigmond, 2011: Impact of polar ozone depletion on subtropical precipitation. Science, 332 (6032), 951-954, doi:10. 
1126/science.1202131, URL http://science.sciencemag.org/content/332/6032/951, http://science.sciencemag.org/content/332/6032/951.full.pdf.

Karnauskas, K. B. and C. C. Ummenhofer, 2014: On the dynamics of the Hadley circulation and subtropical drying. Clim. Dyn., 42, 2259-2269, doi:10.1007/s00382-014-2129-1, URL http: //dx.doi.org/10.1007/s00382-014-2129-1.

Kidston, J. and E. P. Gerber, 2010: Intermodel variability of the poleward shift of the austral jet stream in the CMIP3 integrations linked to biases in 20th century climatology. Geophys. Res. Lett., 37, 09708, doi:10.1029/2010GL042873.

Koch, P., H. Wernli, and H. C. Davies, 2006: An event-based jet-stream climatology and typology. Int. J. Climatol., 26, 283-301.

Langford, A., 1999: Stratosphere-troposphere exchange at the subtropical jet: Contribution to the tropospheric ozone budget at midlatitudes. Geophys. Res. Lett., 26, 2449-2452.

Lee, S. and H.-K. Kim, 2003: The dynamical relationship betweem subtropical and eddy-driven jets. J. Atmos. Sci., 60, 1490-1503.

Lin, M., A. M. Fiore, L. W. Horowitz, A. O. Langford, S. J. Oltmans, D. Tarasick, and H. E. Rieder, 2015: Climate variability modulates western US ozone air quality in spring via deep stratospheric intrusions. Nature Commun., 6.

Lin, M., L. W. Horowitz, S. J. Oltmans, A. M. Fiore, and S. Fan, 2014: Tropospheric ozone trends at Mauna Loa Observatory tied to decadal climate variability. Nature Geosci., 7, 136-143.

Long, C. S., M. Fujiwara, S. Davis, D. M. Mitchell, and C. J. Wright, 2017: Climatology and interannual variability of dynamic variables in multiple reanalyses evaluated by the SPARC 
Reanalysis Intercomparison Project (S-RIP). Atmos. Chem. Phys. Disc., 2017, doi:10.5194/ acp-2017-289, URL http://www . atmos-chem-phys-discuss .net/acp-2017-289/.

Lorenz, D. J. and E. T. DeWeaver, 2007: Tropopause height and zonal wind response to global warming in the IPCC scenario integrations. J. Geophys. Res., 112, D10119, doi: 10.1029/2006JD008087.

Lorenz, D. J. and D. L. Hartmann, 2003: Eddy-zonal flow feedback in the northern hemisphere winter. J. Clim., 16, 1212-1227.

Lucas, C. and H. Nguyen, 2015: Regional characteristics of tropical expansion and the role of climate variability. Journal of Geophysical Research: Atmospheres, 120 (14), 6809-6824, doi:10. 1002/2015JD023130, URL http://dx.doi .org/10.1002/2015JD023130, 2015JD023130.

Lucas, C., H. Nguyen, and B. Timbal, 2012: An observational analysis of southern hemisphere tropical expansion. Journal of Geophysical Research: Atmospheres, 117 (D17), n/a-n/a, doi: 10.1029/2011JD017033, URL http://dx.doi.org/10.1029/2011JD017033, d17112.

Lucas, C., B. Timbal, and H. Nguyen, 2014: The expanding tropics: A critical assessment of the observational and modeling studies. WIRES: Climate Change, 5, 89-112, doi:10.1002/wcc.251, URL http://dx.doi.org/10.1002/wcc. 251

Mann, M. E., S. Rahmstorf, K. Kornhuber, B. A. Steinman, S. K. Miller, and D. Coumou, 2017: Influence of anthropogenic climate change on planetary wave resonance and extreme weather events. Nature Scientific Reports, 7, doi:10.1038/srep45242.

Manney, G. L., M. I. Hegglin, W. H. Daffer, M. J. Schwartz, M. L. Santee, and S. Pawson, 2014: Climatology of upper tropospheric/lower stratospheric (UTLS) jets and tropopauses in MERRA. J. Clim., 27, 3248-3271. 
Manney, G. L., Z. D. Lawrence, and M. I. Hegglin, 2017a: Interannual variability in upper tropospheric jets in reanalyses: Relationships to ENSO and QBO, to be submitted to J. Clim.

Manney, G. L., et al., 2011: Jet characterization in the upper troposphere/lower stratosphere (UTLS): Applications to climatology and transport studies. Atmos. Chem. Phys., 11, 61156137.

Manney, G. L., et al., 2017b: Reanalysis comparisons of upper tropospheric/lower stratospheric jets and multiple tropopauses. Atmos. Chem. Phys., in press, doi:10.5194/acp-2017-400.

Manzini, E., et al., 2014: Northern winter climate change: Assessment of uncertainty in CMIP5 projections related to stratosphere-troposphere coupling. J. Geophys. Res., 119 (13), 7979-7998, doi:10.1002/2013JD021403, URL http://dx.doi.org/10.1002/ 2013JD021403, 2013JD021403.

Martius, O., 2014: A lagrangian analysis of the northern hemisphere subtropical jet. J. Atmos. Sci., 71, 2354-2369.

McLandress, C., T. G. Shepherd, J. F. Scinocca, D. A. Plummer, M. Sigmond, A. I. Jonsson, and M. C. Reader, 2011: Separating the dynamical effects of climate change and ozone depletion. Part II: Southern Hemisphere troposphere. J. Clim., 24, 1850-1868.

Messori, G. and R. Caballero, 2015: On double Rossby wave breaking in the North Atlantic. $J$. Geophys. Res., 120, 11,129-11,150, doi:10.1002/2015JD023854, URL http://dx.doi.org/ 10.1002/2015JD023854.

Messori, G., R. Caballero, and M. Gaetani, 2016: On cold spells in North America and storminess in Western Europe. Geophys. Res. Lett., 6620-6628. 
Molod, A., L. Takacs, M. Suarez, and J. Bacmeister, 2015: Development of the GEOS-5 atmospheric general circulation model: Evolution from MERRA to MERRA-2. Geosci. Model Dev., 8, 1339-1356.

Nicholls, N., 2000: The insignificance of significance testing. Bull. Am. Meteor. Soc., 81, 981-986.

Nuzzo, R., 2014: Statistical errors. Nature, 506, 150-152.

Olsen, M. A., K. Wargan, and S. Pawson, 2016: Tropospheric column ozone response to ENSO in GEOS-5 assimilation of OMI and MLS ozone data. Atmos. Chem. Phys., 16, 7091-7103, doi: 10.5194/acp-16-7091-2016, URL http://www . atmos-chem-phys .net/16/7091/2016/.

Overland, J. E. and M. Wang, 2005: The Arctic climate paradox: The recent decrease of the Arctic Oscillation. Geophys. Res. Lett., 32, L06701, doi:10.1029/2004GL021752.

Overland, J. E., et al., 2016: Nonlinear response of mid-latitude weather to the changing Arctic. Nature Climate Change, 6 (11), 992-999.

Peña-Ortiz, C., D. Gallego, P. Ribera, P. Ordonez, and M. D. C. Alvarez-Castro, 2013: Observed trends in the global jet stream characteristics during the second half of the 20th century. $J$. Geophys. Res., 118 (7), 2702-2713, doi:10.1002/jgrd.50305, URL http://dx.doi.org/10. 1002/jgrd. 50305.

Pinto, J. G., I. Gmara, G. Masato, H. F. Dacre, T. Woollings, and R. Caballero, 2014: Largescale dynamics associated with clustering of extratropical cyclones affecting Western Europe. $J$. Geophys. Res., 119, 13,704-13,719, doi:10.1002/2014JD022305, URL http://dx.doi .org/ 10.1002/2014JD022305.

Pinto, S., Joaquim G.and Zacharias, A. H. Fink, and U. Leckebusch, Gregor C.and Ulbrich, 2009: Factors contributing to the development of extreme North Atlantic cyclones and their 
relationship with the NAO. Clim. Dyn., 32, 711-737, doi:10.1007/s00382-008-0396-4, URL http://dx.doi.org/10.1007/s00382-008-0396-4.

Price, C., L. Stone, A. Huppert, B. Rajagopalan, and P. Alpert, 1998: A possible link between El Niño and precipitation in Israel. Geophys. Res. Lett., 25, 3963-3966, doi:10.1029/ 1998GL900098, URL http://dx.doi.org/10.1029/1998GL900098.

Raible, C. C., U. Luksch, and K. Fraedrich, 2004: Precipitation and Northern Hemisphere regimes. Atmos. Sci. Lett., 5, 43-55, doi:10.1016/j.atmoscilet.2003.12.001, URL http://dx.doi.org/ 10.1016/j.atmoscilet.2003.12.001.

Rienecker, M. M. et al., 2011: MERRA: NASA's Modern-Era Retrospective Analysis for Research and Applications. J. Clim., 24, 3624-3648.

Robinson, W. A., 2006: On the self-maintenance of midlatitude jets. J. Atmos. Sci., 63, 2109-2122.

Röthlisberger, M., S. Pfahl, and O. Martius, 2016: Regional-scale jet waviness modulates the occurrence of midlatitude weather extremes. Geophysical Research Letters, 43 (20).

Saha, S. et al., 2010: The NCEP Climate Forecast System Reanalysis. Bull. Am. Meteor. Soc., 91, $1015-1057$.

Santer, B. D. et al., 2003: Behavior of tropopause height and atmospheric temperature in models, reananlyses, and observations: Decadal changes. J. Geophys. Res., 108, 4002, doi:10.1029/ 2002JD002258.

Sardeshmukh, P. D. and B. J. Hoskins, 1988: The generation of global rotational flow by steady idealized tropical divergence. J. Atmos. Sci., 45, 1228-1251.

Scaife, A. A., et al., 2012: Climate change projections and stratosphere-troposphere interaction. Clim. Dyn., 38 (9-10), 2089-2097. 
Screen, J. A. and I. Simmonds, 2014: Amplified mid-latitude planetary waves favour particular regional weather extremes. Nature Climate Change, 4 (8), 704-709.

Screen, J. A., I. Simmonds, C. Deser, and R. Tomas, 2013: The atmospheric response to three decades of observed Arctic sea ice loss. J. Clim., 26 (4), 1230-1248.

Seidel, D. J., Q. Fu, W. J. Randel, and T. J. Reichler, 2008: Widening of the tropical belt in a changing climate. Nature Geoscience, 1, 21-24.

Seidel, D. J. and W. J. Randel, 2006: Variability and trends in the global tropopause estimated from radiosonde data. J. Geophys. Res., 111, D21101, doi:10.1029/2006JD007363.

Serreze, M. C. and R. G. Barry, 2011: Processes and inmpacts of Arctic amplification: A research synthesis. Global and Planetary Change, 77, 85-96.

Shepherd, T. G., 2016: Effects of a warming Arctic. Science, 353 (6303), 989-990, doi:10.1126/ science.aag2349, URL http://science. sciencemag. org/content/353/6303/989, http: //science.sciencemag. org/content/353/6303/989.full.pdf.

Sigmond, M. and J. F. Scinocca, 2010: The influence of the basic state on the Northern Hemisphere circulation response to climate change. J. Clim., 23, 1434-1446.

Simpson, I. R., M. Blackburn, and J. D. Haigh, 2009: The role of eddies in driving the tropospheric response to stratospheric heating perturbations. J. Atmos. Sci., 66 (5), 1347-1365, doi:10.1175/ 2008JAS2758.1.

Simpson, I. R. and L. M. Polvani, 2016: Revisiting the relationship between jet position, forced response, and annular mode variability in the southern midlatitudes. Geophys. Res. Lett., 43 (6), 2896-2903, doi:10.1002/2016GL067989, URL http://dx.doi .org/10.1002/ 2016GL067989, 2016GL067989. 
Simpson, I. R., T. A. Shaw, and R. Seager, 2014: A diagnosis of the seasonally and longitudinally varying midlatitude circulation response to global warming. J. Atmos. Sci., 71 (7), 2489-2515, doi:10.1175/JAS-D-13-0325.1.

Son, S.-W. et al., 2010: Impact of stratospheric ozone on Southern Hemisphere circulation change: A multimodel assessment. J. Geophys. Res., 115, D00M07, doi:10.1029/2010GL014271.

Staten, P. W., K. M. Grise, and S. M. Davis, 2016: The width of the tropics: Climate variations and their impacts. SPARC Newsletter, 46, 26-31.

Strong, C. and R. E. Davis, 2007: Winter jet stream trends over the Northern Hemisphere. Q. J. R. Meteorol. Soc., 133, 2109-2115.

Strong, C. and R. E. Davis, 2008: Variability in the position and strength of winter jet stream cores related to Northern Hemisphere teleconnections. J. Clim., 21, 584-592.

Takacs, L. L., M. J. Suárez, and R. Todling, 2016: Maintaining atmospheric mass and water balance in reanalyses. Q. J. R. Meteorol. Soc., 142, 1565-1573.

Thompson, D. W., S. Solomon, P. J. Kushner, M. H. Grise, and D. J. Karoly, 2011: Signatures of the antarctic ozone hole in Southern Hemisphere surface climate change. Nature Geoscience, $\mathbf{4}$, 741-749.

Thompson, D. W. J., J. M. Wallace, and G. C. Hegerl, 2000: Annular modes in the extratropical circulation. Part II: Trends. J. Clim., 13 (5), 1018-1036, doi:10.1175/1520-0442(2000)013〈1018: AMITEC $>2.0 . C O ; 2, \quad$ URL https://doi.org/10.1175/1520-0442(2000)013<1018: AMITEC>2.0.CO;2, $\quad$ https://doi .org/10.1175/1520-0442(2000)013<1018: AMITEC>2.0.CO;2. 
Wang, L. and S. Lee, 2016: The role of eddy diffusivity on a poleward jet shift. J. Atmos. Sci., 73 (12), 4945-4958.

Wargan, K., G. Labow, S. Frith, S. Pawson, N. Livesey, and G. Partyka, 2017: Evaluation of the ozone fields in NASA's MERRA-2 reanalysis. J. Clim., 30, 2961-2988, doi: 10.1175/JCLI-D-16-0699.1.

Waugh, D. W., C. I. Garfinkel, and L. M. Polvani, 2015: Drivers of the recent tropical expansion in the Southern Hemisphere: Changing SSTs or ozone depletion? J. Clim., 28, 6581-6586, doi:10.1175/JCLI-D-15-0138.1, URL http://dx.doi .org/10.1175/JCLI-D-15-0138.1.

Wilks, D. S., 2011: Statistical Methods in the Atmospheric Sciences. 3d ed., Elsevier Academic Press, volume 100, International Geophysics Series.

WMO, 2011: Scientific assessment of ozone depletion: 2010. Global Ozone Res. and Monit. Proj. Rep. 52, Geneva, Switzerland.

Woollings, T., C. Czuchnicki, and C. Franzke, 2014: Twentieth century North Atlantic jet variability. Q. J. Roy. Meteorol. Soc., 140 (680), 783-791.

Woollings, T., A. Hannachi, and B. Hoskins, 2010: Variability of the North Atlantic eddy-driven jet stream. Q. J. R. Meteorol. Soc., 136, 856-868.

Woollings, T., L. Papritz, C. Mbengue, and T. Spengler, 2016: Diabatic heating and jet stream shifts: A case study of the 2010 negative North Atlantic Oscillation winter. Geophys. Res. Lett., $43(18)$.

Woollings, T., J. G. Pinto, and J. A. Santos, 2011: Dynamical evolution of North Atlantic ridges and poleward jet stream displacements. J. Atmos. Sci., 68, 954-963. 
Xie, Z., Y. Du, and S. Yang, 2015: Zonal extension and retraction of the subtropical westerly jet stream and evolution of precipitation over East Asia and the Western Pacific. J. Clim., 28, 6783-6798, doi:10.1175/JCLI-D-14-00649.1.

Zappa, G., B. J. Hoskins, and T. G. Shepherd, 2015: Improving climate change detection through optimal seasonal averaging: the case of the North Atlantic jet and European precipitation. $J$. Clim., 28 (16), 6381-6397. 


\section{LIST OF FIGURES}

Fig. 1. (Top) climatological jet frequency distributions (expressed as a percentage) as (left) maps and (right) cross-sections, and differences between distributions in the first and last ten years of the record (expressed in percentage points). From the MERRA-2 reanalysis for DJF. The overlaid black contours show climatological frequency contours of 15,30 , and $45 \%$ on the maps, and 2,3 , and $4 \%$ on the cross-sections.

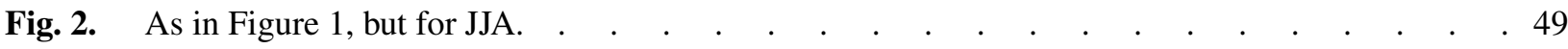

Fig. 3. As in Figure 1, but for MAM. . . . . . . . . . . . . . . . . . . . . . . . . $\quad$. 50

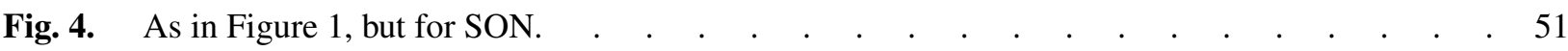

Fig. 5. Time series of subtropical jet latitudes for five reanalyses, 2 hemispheres, DJF \& JJA. The lower panel of each pair shows the fits to slopes and the 1-sigma uncertainty envelope in those fits.

Fig. 6. As in Figure 5, but for subtropical jet altitudes.

Fig. 8. Bar charts of global subtropical jet and NH/SH subtropical jet separation trends as a function of longitude in $20^{\circ}$ bins, for DJF showing five reanalyses. Layout is as in Figure 4.

Fig. 9. Bar charts of global subtropical jet and NH/SH subtropical jet separation trends as a function of longitude in $20^{\circ}$ bins, for JJA showing five reanalyses. Layout is as in Figure 4.

Fig. 10. As in Figure 5, but for the polar jet.

Fig. 11. As in Figure 6, but for the polar jet. DJF \& JJA.

Fig. 12. Bar charts of global polar jet and polar/subtropical jet separation trends as a function of month, season, and annual, showing five reanalyses. Layout is as in Figure 4.

Fig. 13. Bar charts of global polar jet and polar/subtropical jet separation trends as a function of longitude in $20^{\circ}$ bins, for DJF showing five reanalyses.

Fig. 14. Bar charts of global polar jet and polar/subtropical jet separation trends as a function of longitude in $20^{\circ}$ bins, for JJA showing five reanalyses.

Fig. 15. Matrix plots for the subtropical jet showing colored boxes for MERRA-2 (red, upper left of each season / longitude region square), ERA-I (blue, upper right), JRA-55 (purple, lower left), and CFSR (green, lower right) where the signs of trends agree among all four of those reanalyses, and where the trend for that reanalysis is greater than the $1-\sigma$ uncertainty in that slope. Positive (negative) trends are indicated by bold (pale) colors. Plus signs indicate cases where the permutation analysis (see text) shows the slope to be significant at the $95 \%$ confidence level. The $\mathrm{NH}(\mathrm{SH})$ is shown on the left (right), and the diagnostics are arranged as in Figure 4.

Fig. 16. As in Figure 15, but for the polar jets. The diagnostics are arranged as in Figure 12. 

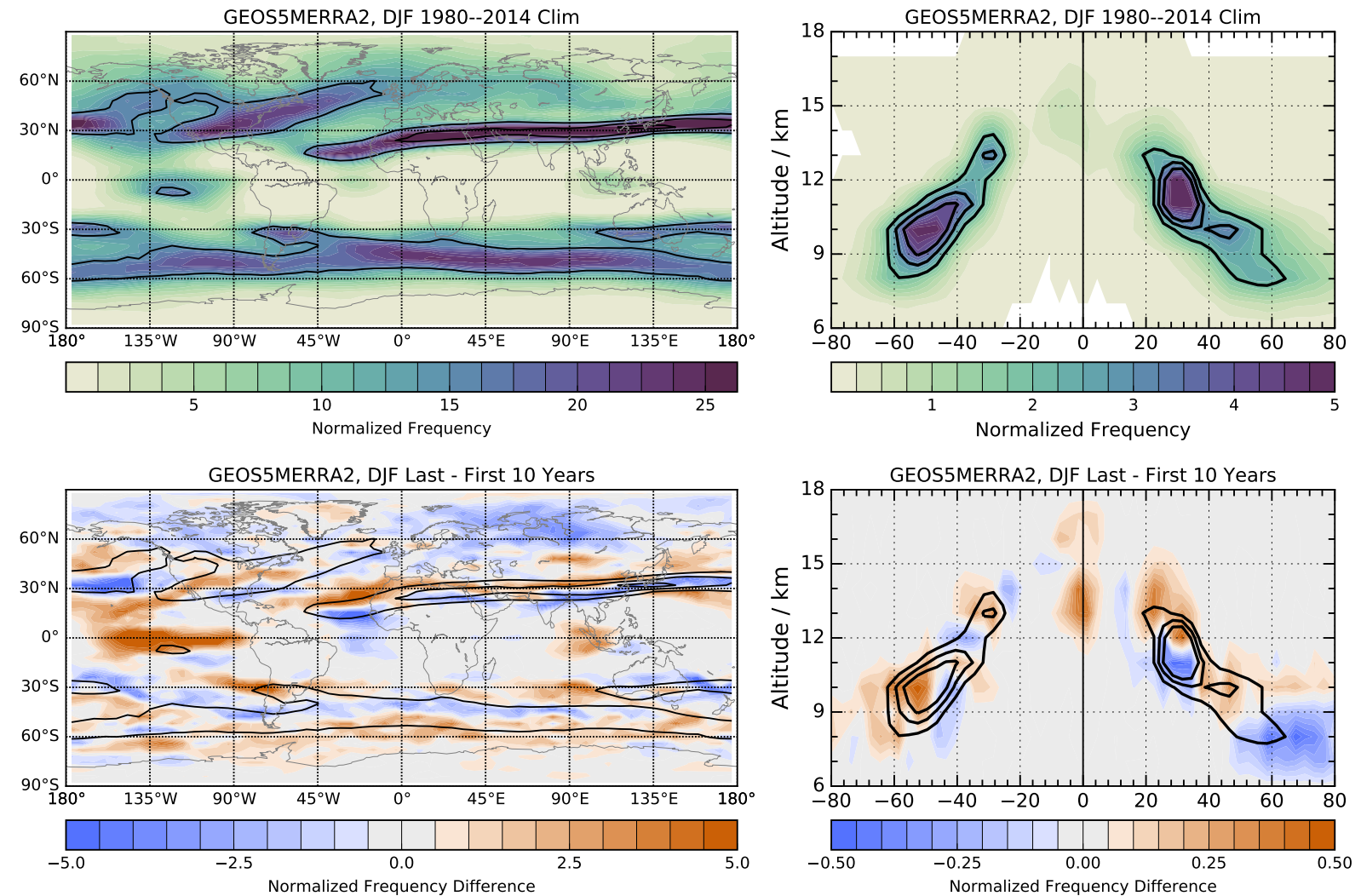

FIG. 1. (Top) climatological jet frequency distributions (expressed as a percentage) as (left) maps and (right) cross-sections, and differences between distributions in the first and last ten years of the record (expressed in percentage points). From the MERRA-2 reanalysis for DJF. The overlaid black contours show climatological frequency contours of 15,30 , and $45 \%$ on the maps, and 2,3 , and $4 \%$ on the cross-sections. 

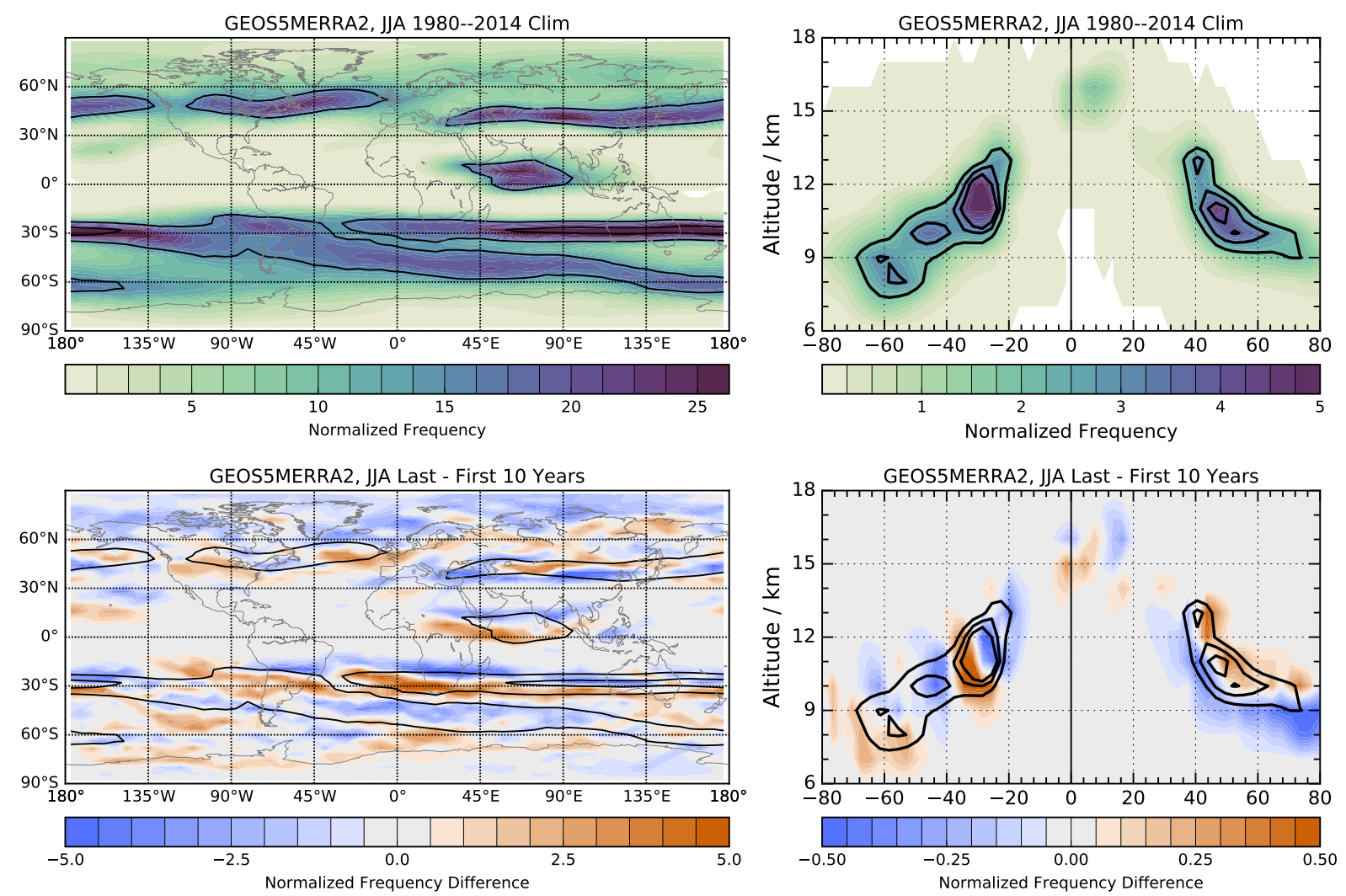

FIG. 2. As in Figure 1, but for JJA. 

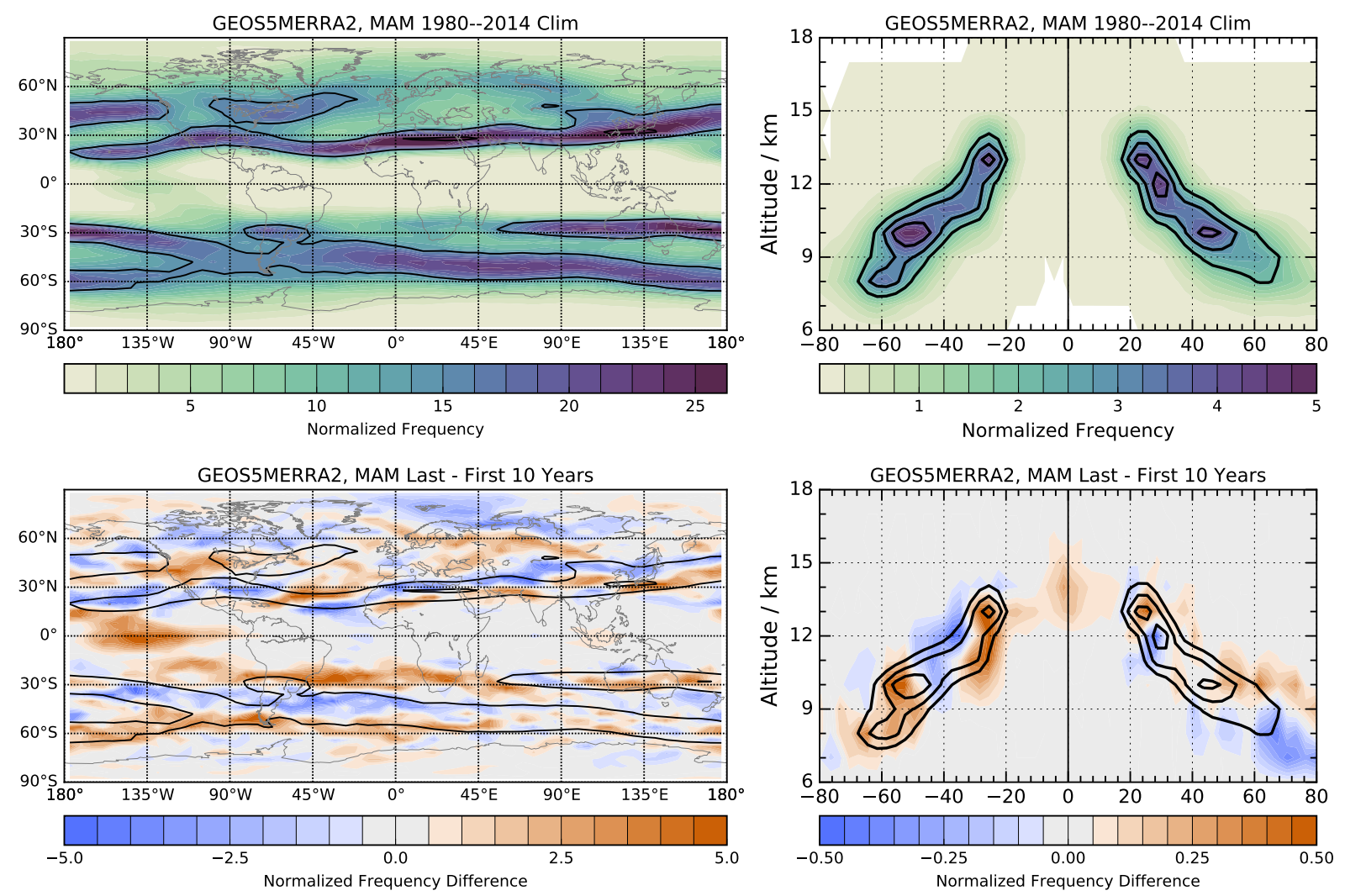

FIG. 3. As in Figure 1, but for MAM. 

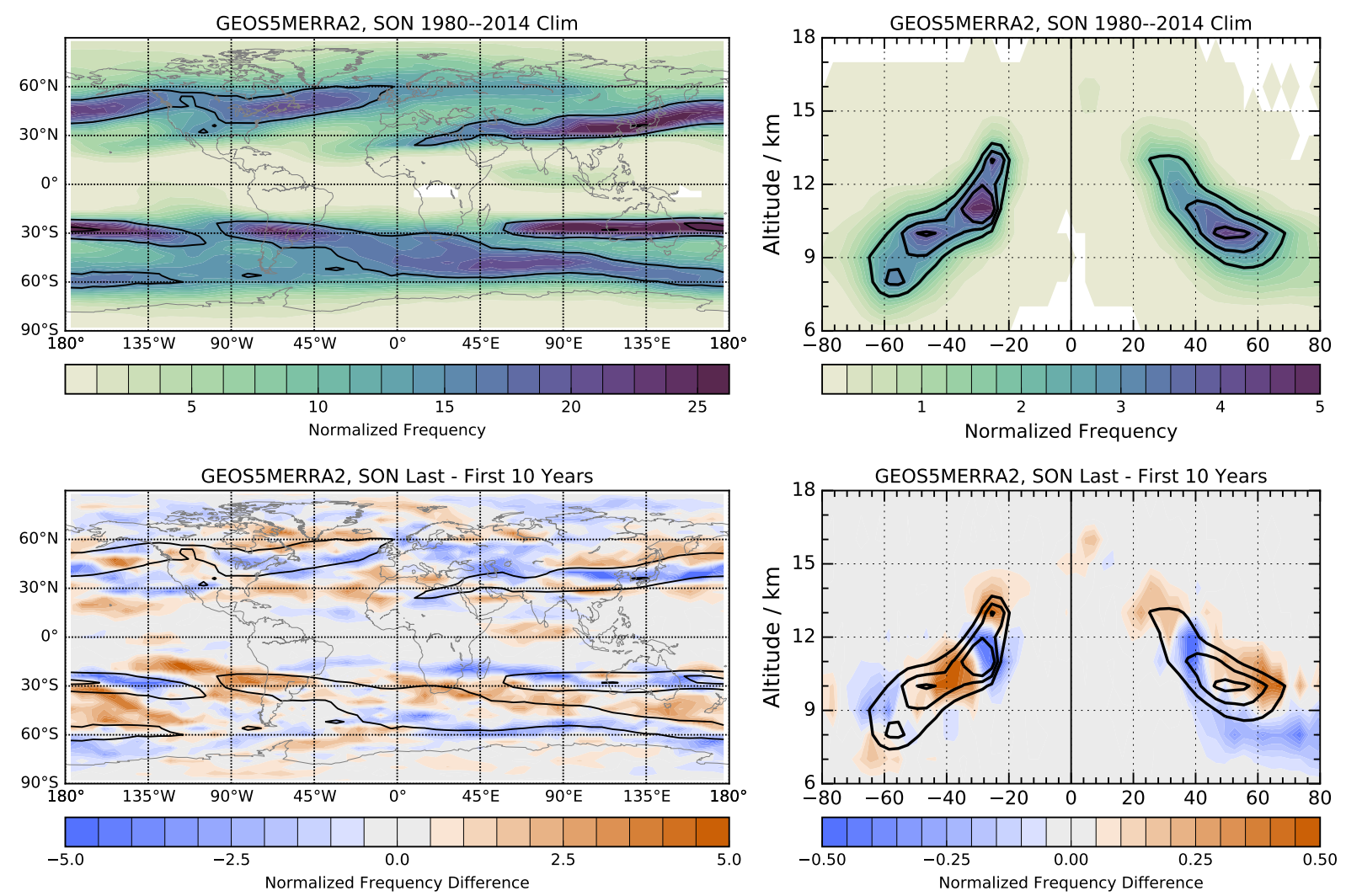

FIG. 4. As in Figure 1, but for SON. 

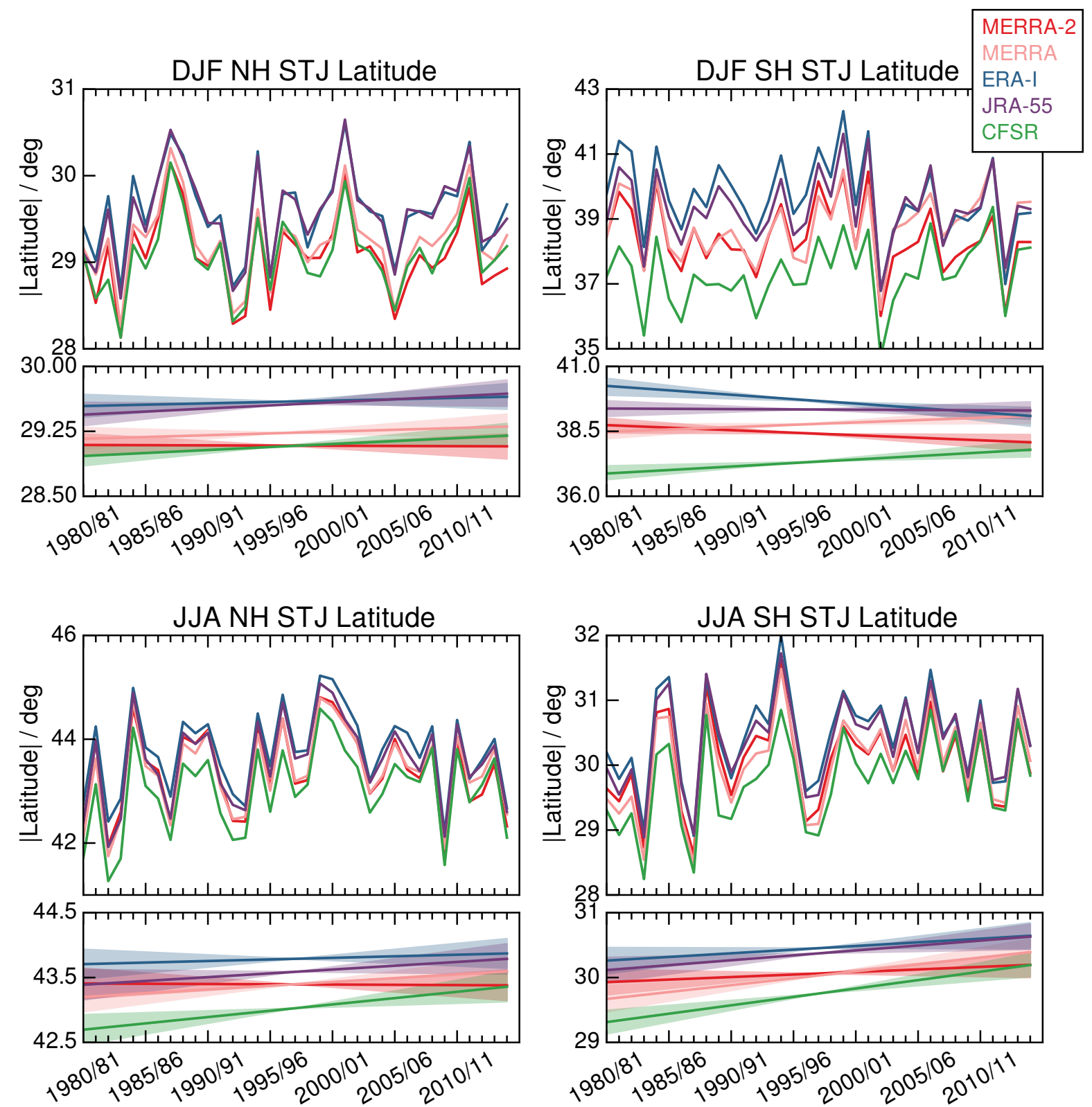

FIG. 5. Time series of subtropical jet latitudes for five reanalyses, 2 hemispheres, DJF \& JJA. The lower panel

of each pair shows the fits to slopes and the 1-sigma uncertainty envelope in those fits. 


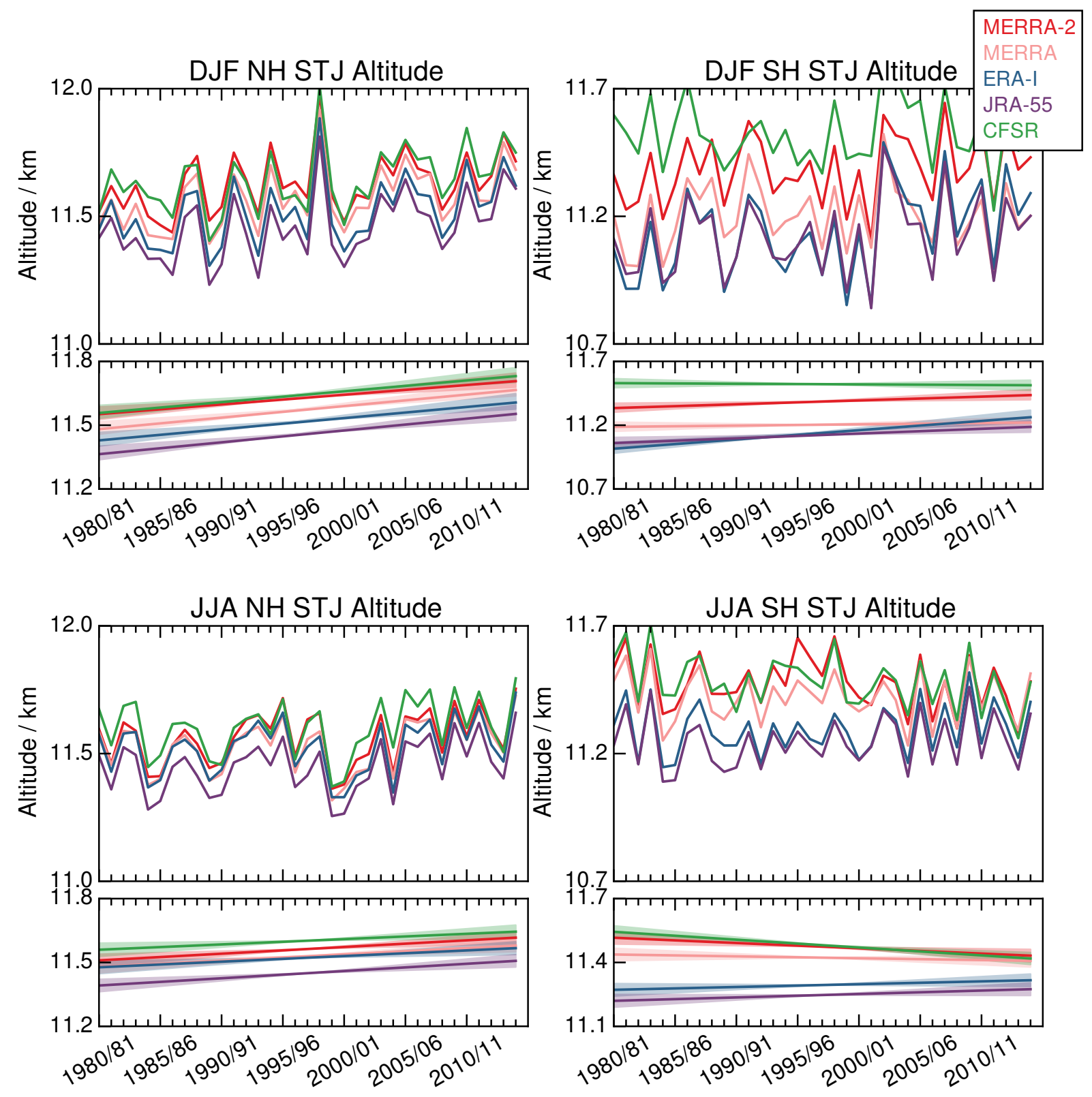

FIG. 6. As in Figure 5, but for subtropical jet altitudes. 

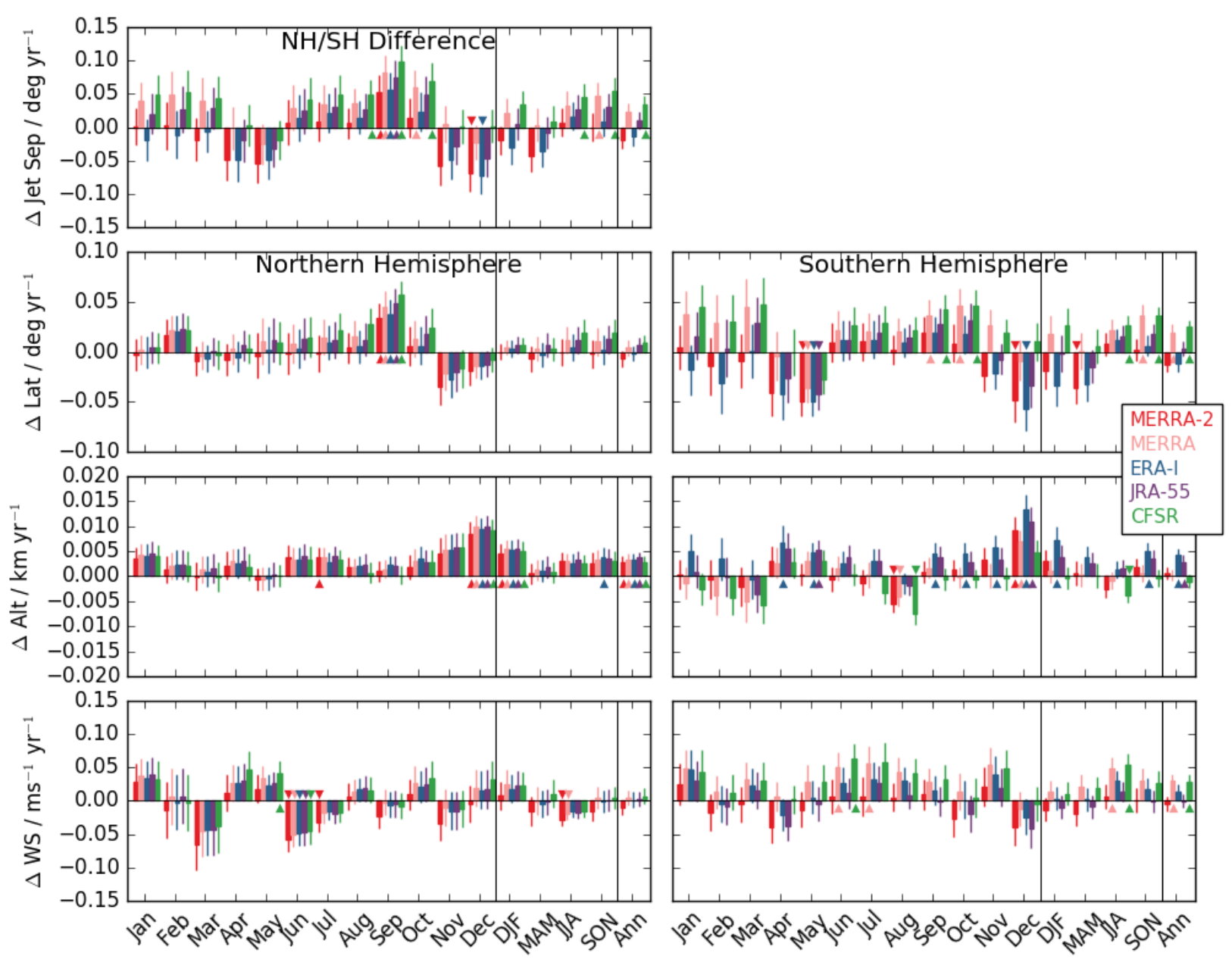

FIG. 7. Bar charts of global subtropical jet and NH/SH subtropical jet separation as a function of month, season, and annual, showing five reanalyses. The bars show the slopes of the fits and the error bars (centered about the top of the bars) the 1-sigma uncertainty in that slope. Note that, in this and similar succeeding figures, absolute value of latitude is used, so positive slopes (bars extending upward from the zero line) indicate a poleward shift in both hemispheres. The zero line in each case indicates no trend in the quantity shown. Triangles indicate cases where the permutation analysis (see text) shows the slope to be significant at the 95\% confidence level. 

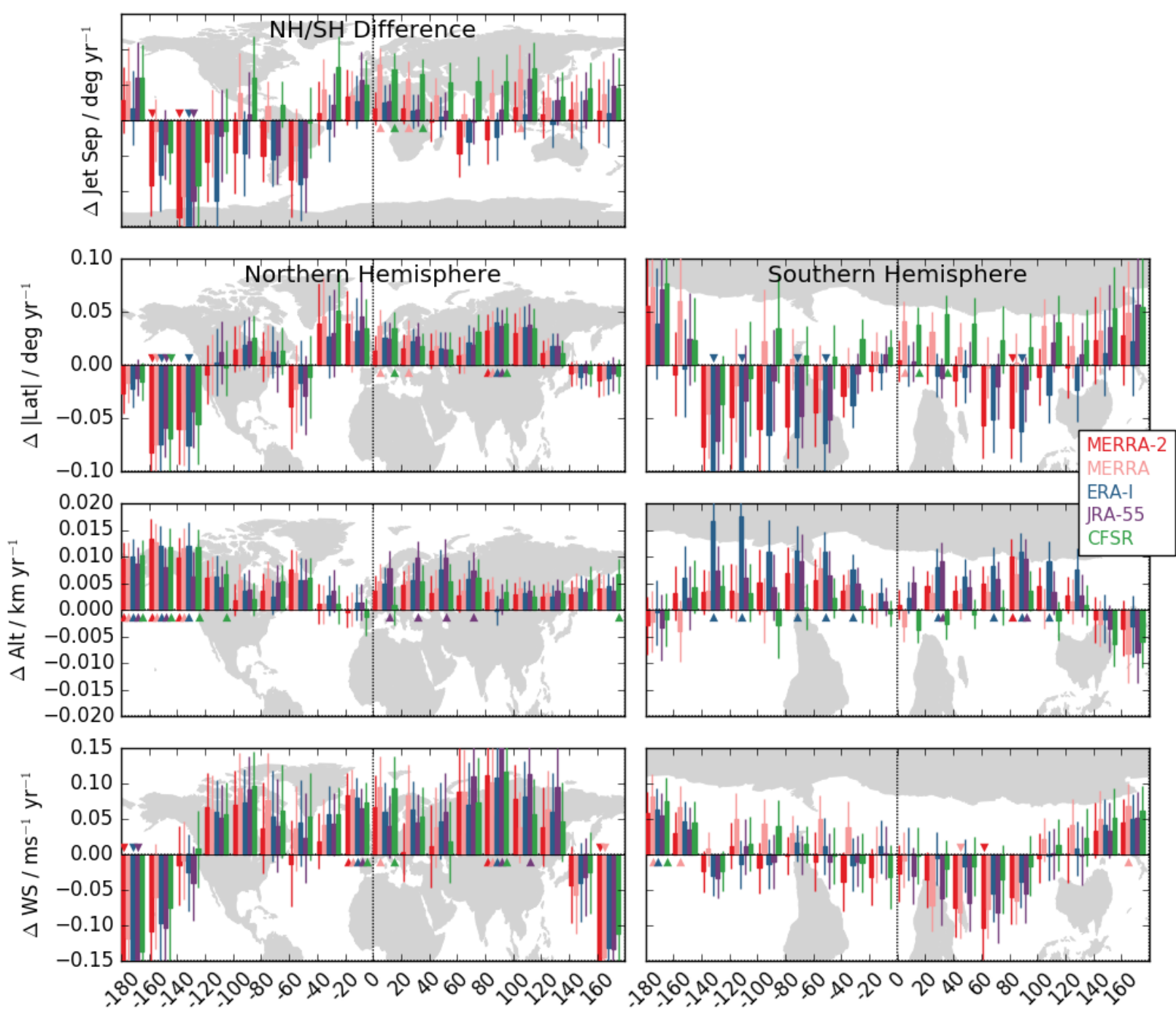

FIG. 8. Bar charts of global subtropical jet and NH/SH subtropical jet separation trends as a function of

longitude in $20^{\circ}$ bins, for DJF showing five reanalyses. Layout is as in Figure 4. 

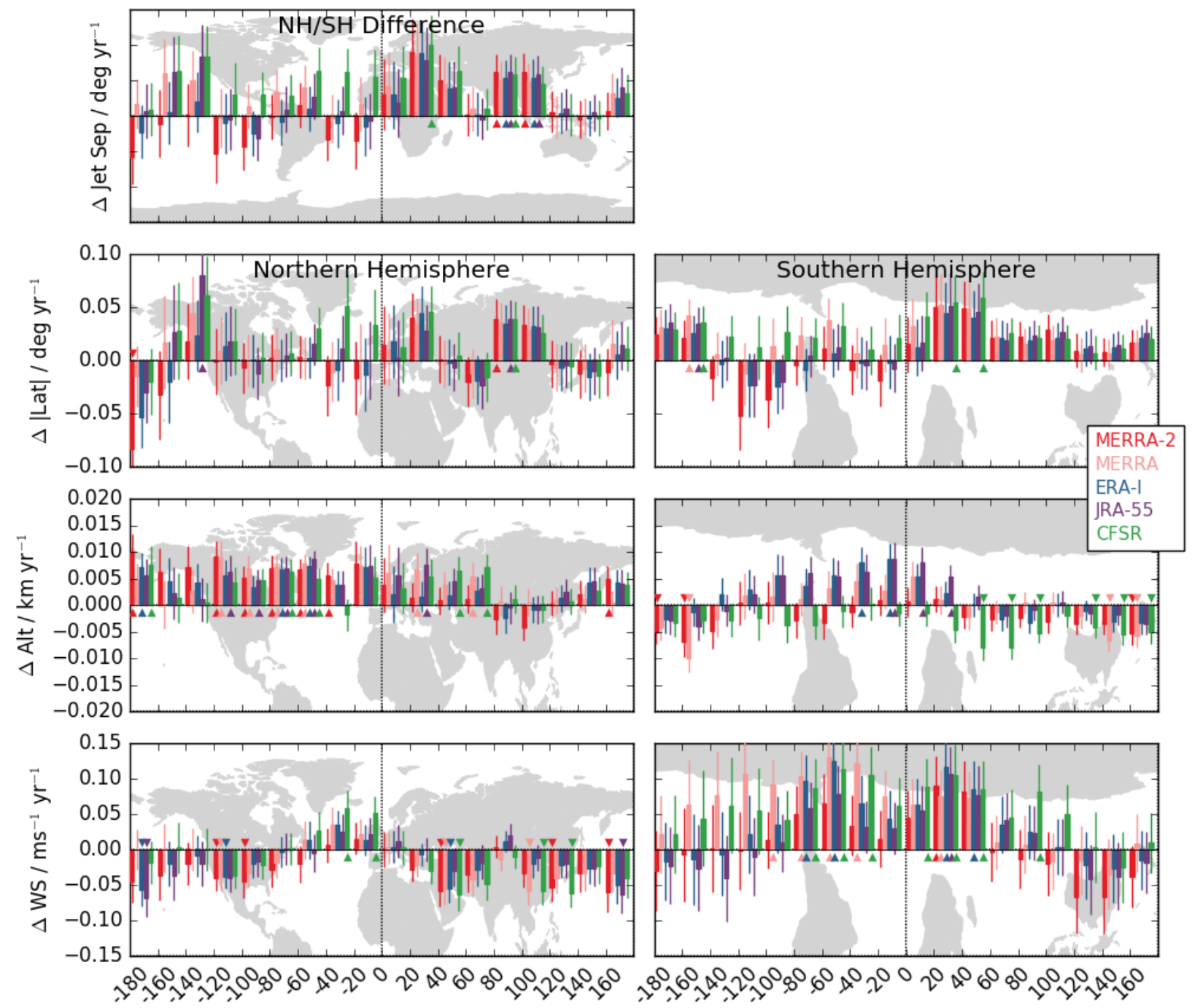

FIG. 9. Bar charts of global subtropical jet and NH/SH subtropical jet separation trends as a function of

longitude in $20^{\circ}$ bins, for JJA showing five reanalyses. Layout is as in Figure 4. 

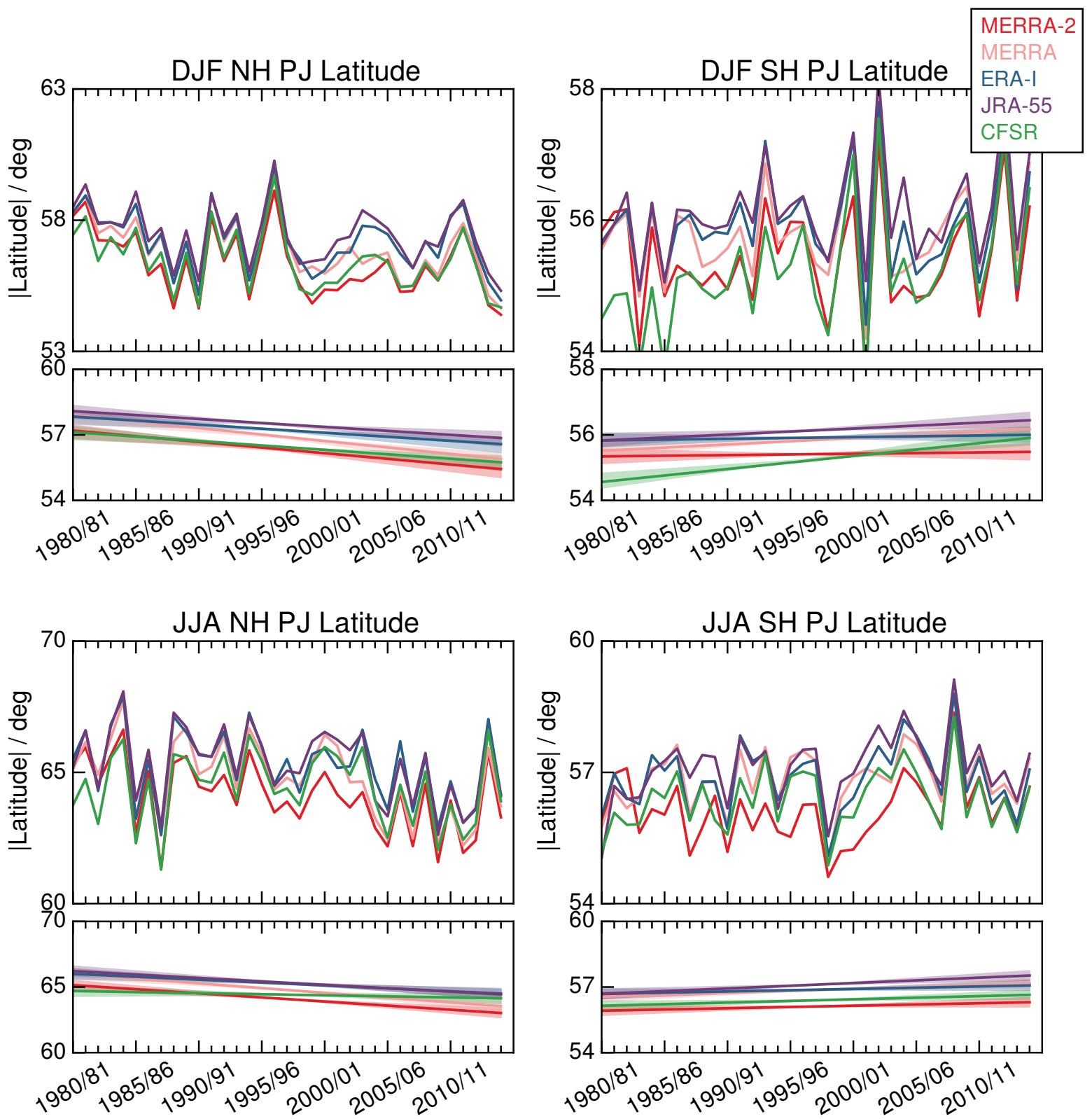

FIG. 10. As in Figure 5, but for the polar jet. 


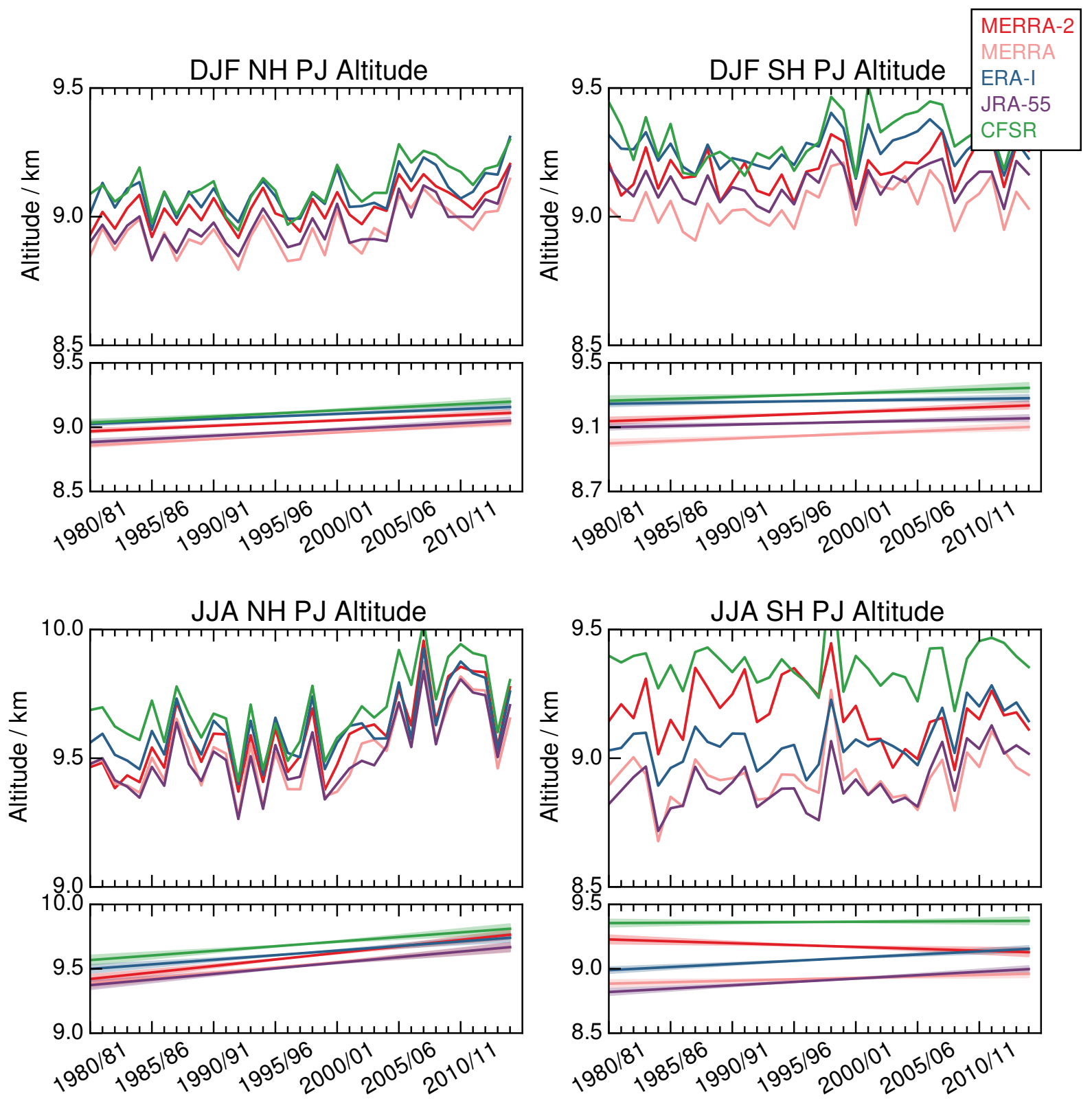

FIG. 11. As in Figure 6, but for the polar jet. DJF \& JJA. 


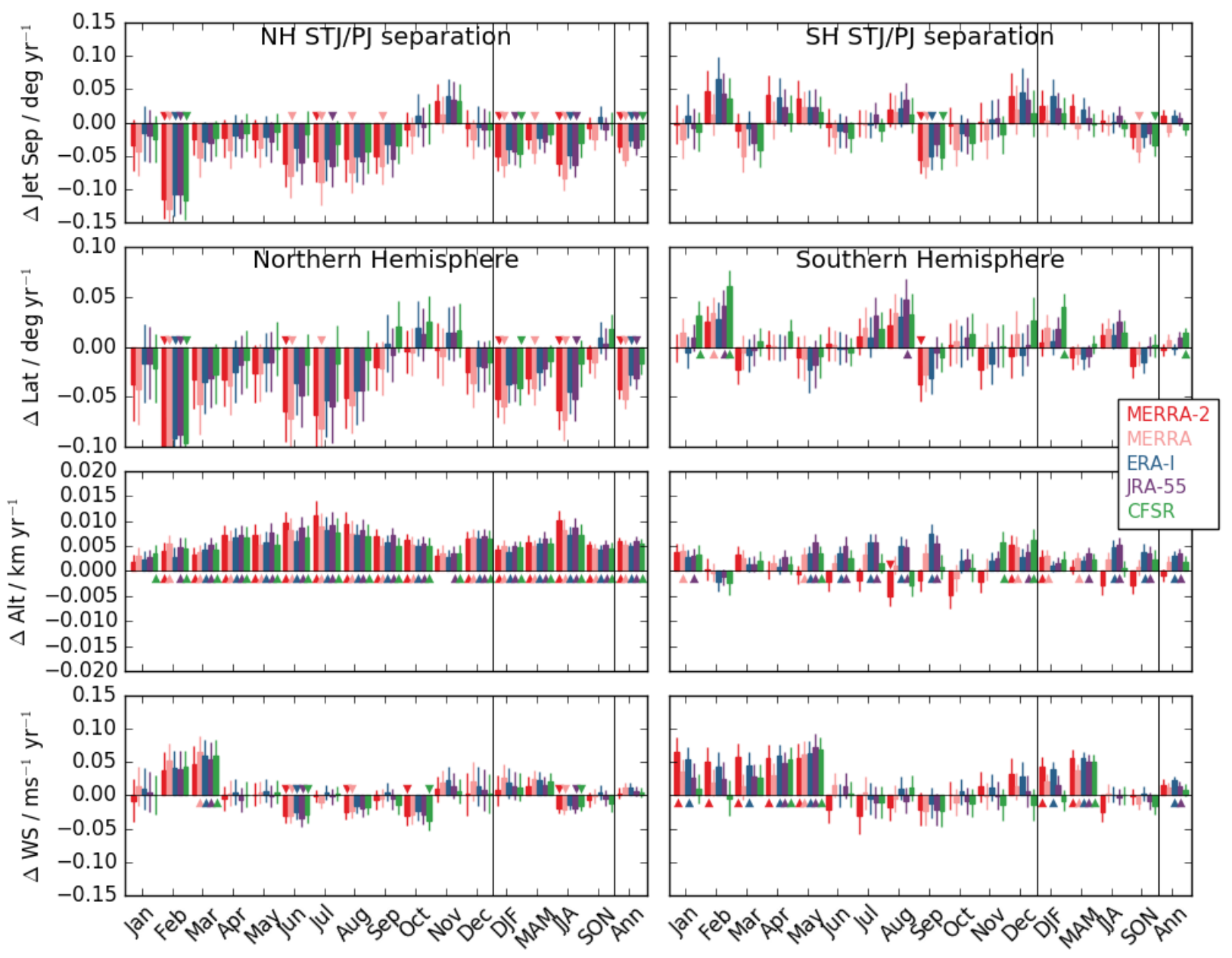

FIG. 12. Bar charts of global polar jet and polar/subtropical jet separation trends as a function of month, season, and annual, showing five reanalyses. Layout is as in Figure 4. 

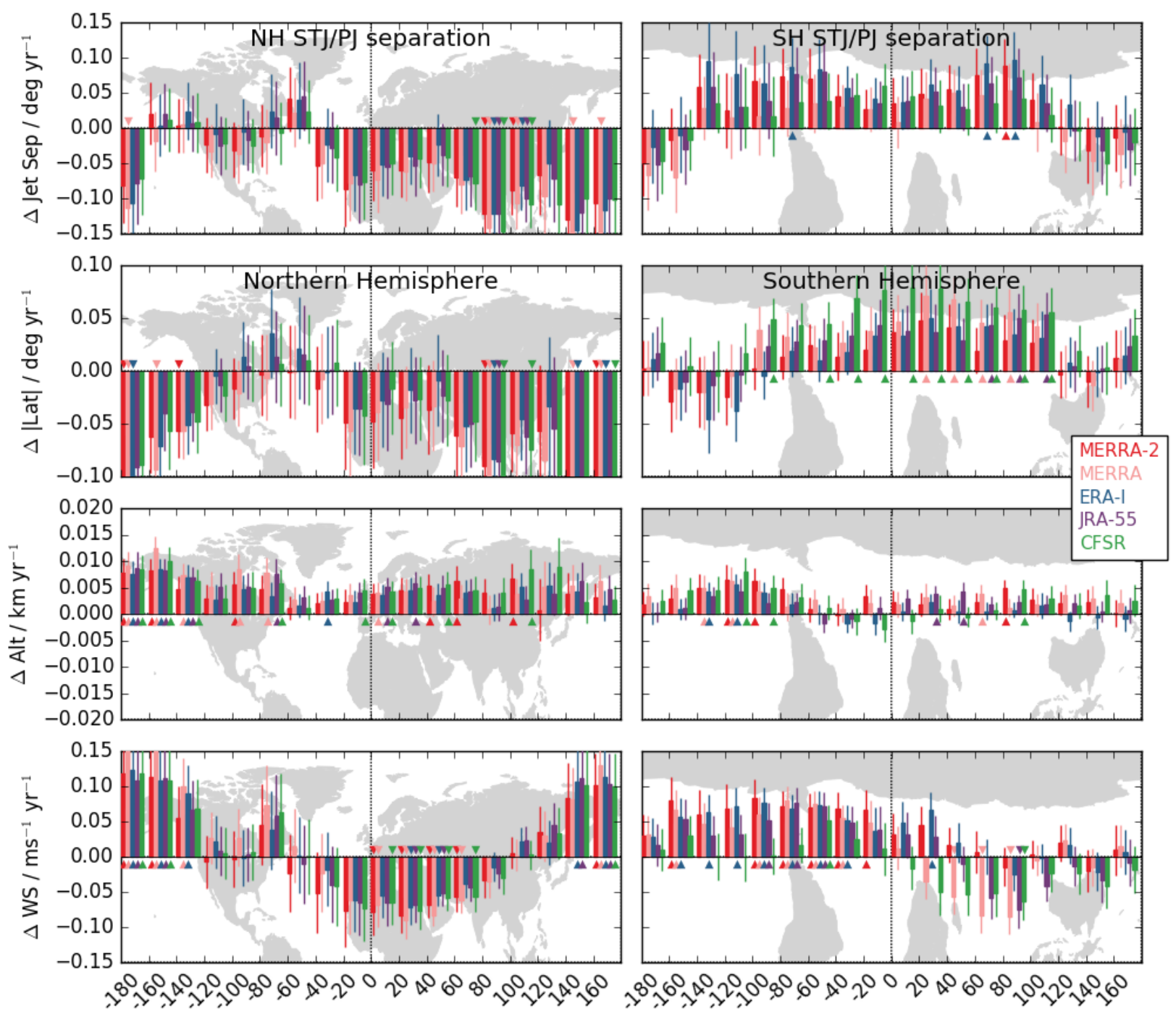

FIG. 13. Bar charts of global polar jet and polar/subtropical jet separation trends as a function of longitude in

$20^{\circ}$ bins, for DJF showing five reanalyses. 

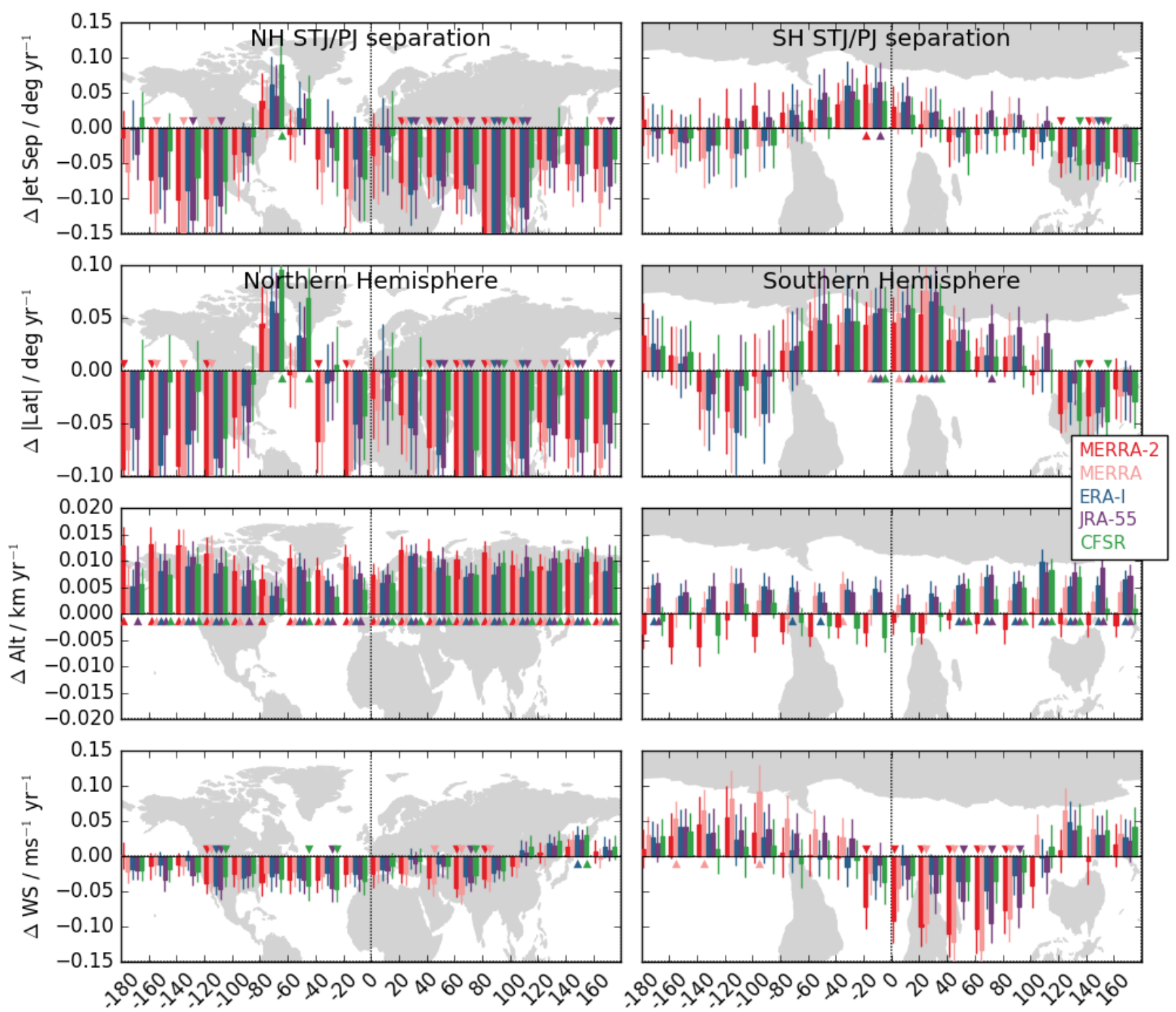

FIG. 14. Bar charts of global polar jet and polar/subtropical jet separation trends as a function of longitude in

$20^{\circ}$ bins, for JJA showing five reanalyses. 

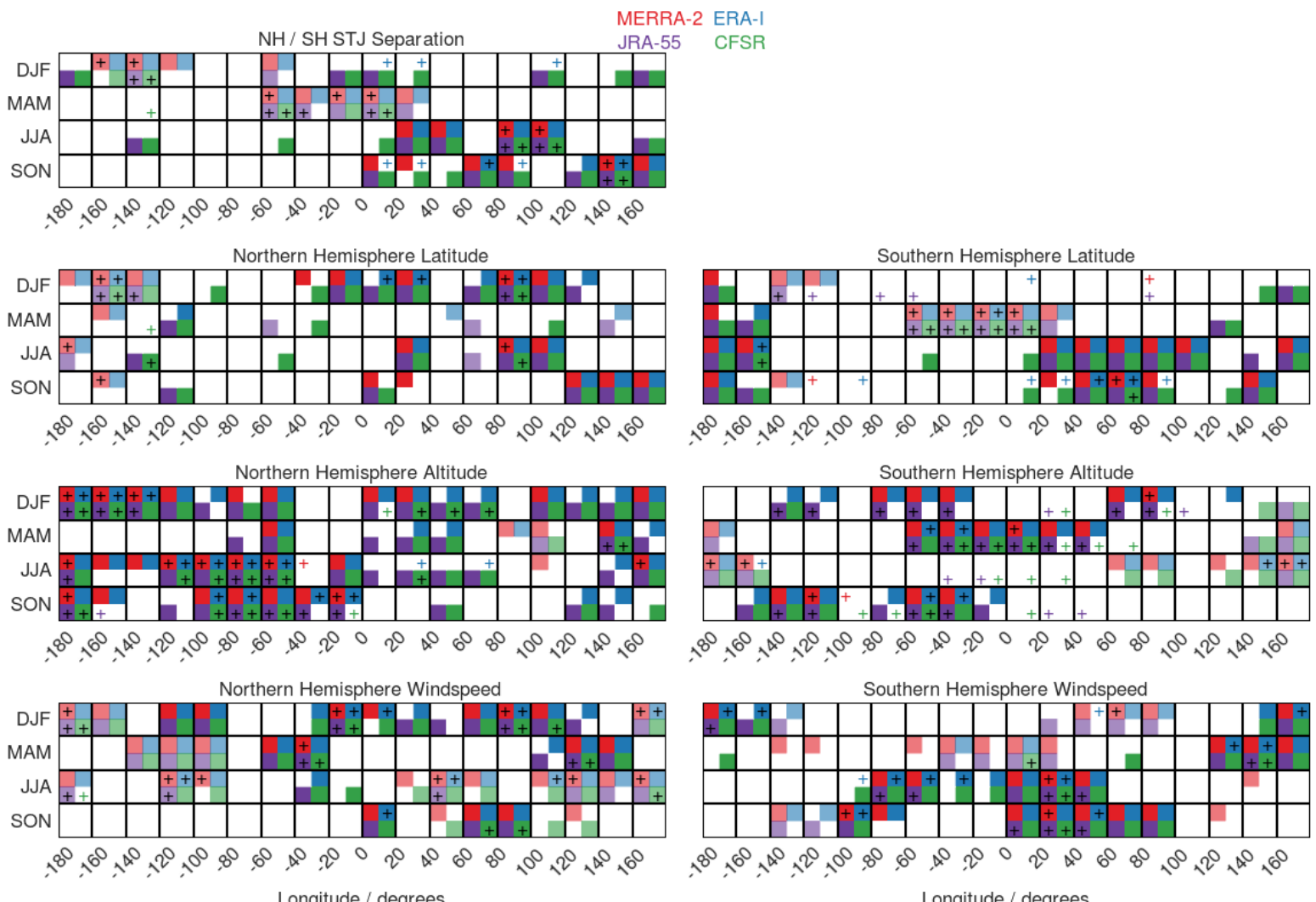

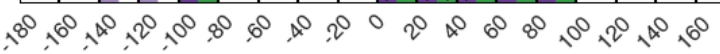

Longitude / degrees

FIG. 15. Matrix plots for the subtropical jet showing colored boxes for MERRA-2 (red, upper left of each season / longitude region square), ERA-I (blue, upper right), JRA-55 (purple, lower left), and CFSR (green, lower right) where the signs of trends agree among all four of those reanalyses, and where the trend for that reanalysis is greater than the $1-\sigma$ uncertainty in that slope. Positive (negative) trends are indicated by bold (pale) colors. Plus signs indicate cases where the permutation analysis (see text) shows the slope to be significant at the 95\% confidence level. The NH (SH) is shown on the left (right), and the diagnostics are arranged as in Figure 4. 

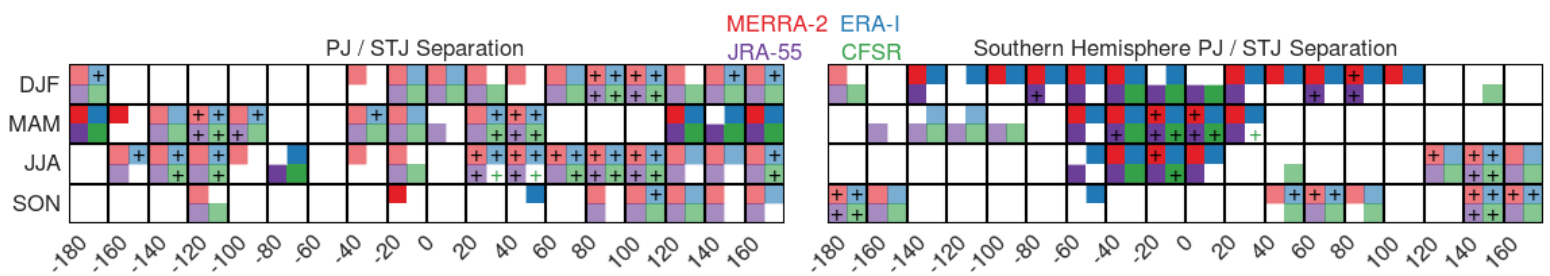

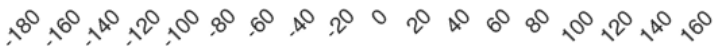
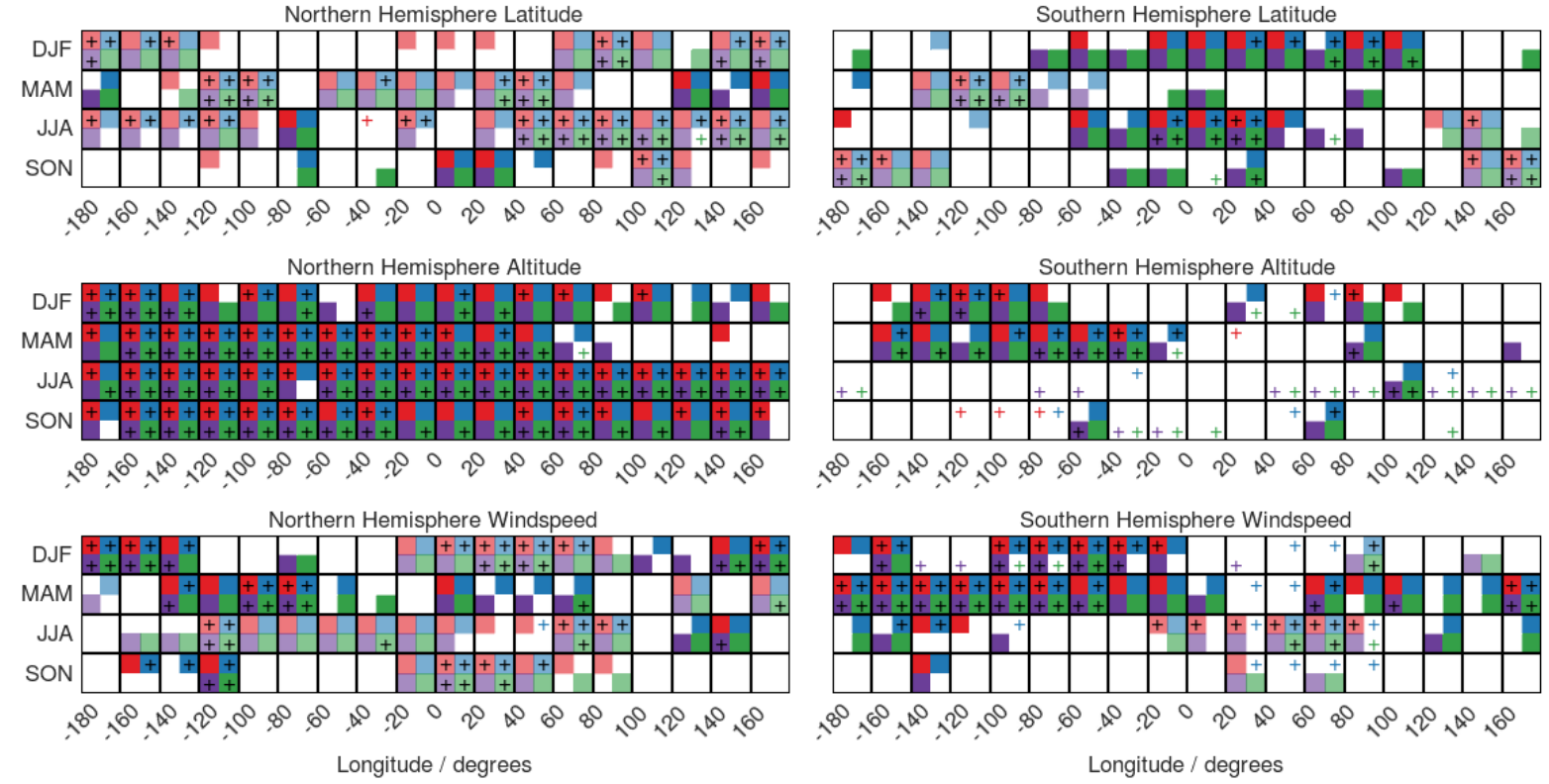

FIG. 16. As in Figure 15, but for the polar jets. The diagnostics are arranged as in Figure 12. 